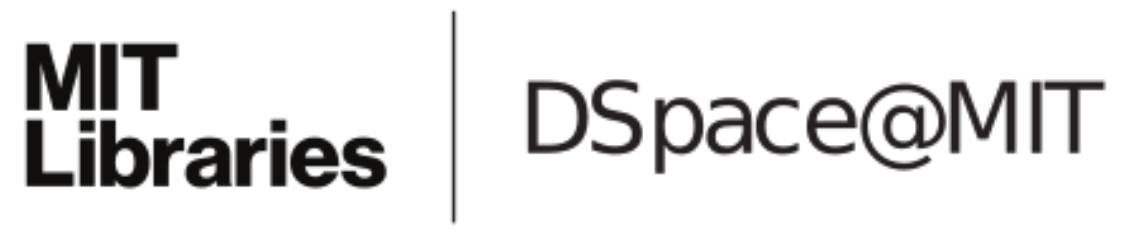

\author{
MIT Open Access Articles
}

\section{Circulation and Stirring in the Southeast Pacific Ocean and the Scotia Sea Sectors of the Antarctic Circumpolar Current}

The MIT Faculty has made this article openly available. Please share how this access benefits you. Your story matters.

Citation: Balwada, Dhruv; Speer, Kevin G.; LaCasce, Joseph H.; Owens, W. Brechner; Marshall, John and Ferrari, Raffaele. " Circulation and Stirring in the Southeast Pacific Ocean and the Scotia Sea Sectors of the Antarctic Circumpolar Current a ." Journal of Physical Oceanography 46, no. 7 (July 2016): 2005-2027. (c) 2016 American Meteorological Society

As Published: http://dx.doi.org/10.1175/JPO-D-15-0207.1

Publisher: American Meteorological Society

Persistent URL: http://hdl.handle.net/1721.1/109082

Version: Final published version: final published article, as it appeared in a journal, conference proceedings, or other formally published context

Terms of Use: Article is made available in accordance with the publisher's policy and may be subject to US copyright law. Please refer to the publisher's site for terms of use. 


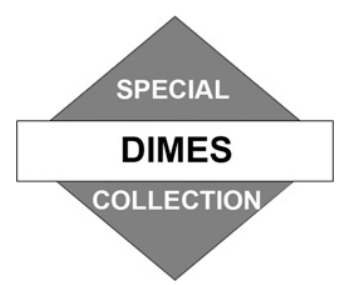

\title{
Circulation and Stirring in the Southeast Pacific Ocean and the Scotia Sea Sectors of the Antarctic Circumpolar Current ${ }^{a}$
}

\author{
Dhruv Balwada And Kevin G. SPeER \\ Department of Earth, Ocean, and Atmospheric Science, and Geophysical Fluid Dynamics Institute, Florida \\ State University, Tallahassee, Florida \\ JOSEPH H. LACASCE \\ Department of Geosciences, University of Oslo, Oslo, Norway \\ W. BRECHNER OWENS \\ Department of Physical Oceanography, Woods Hole Oceanographic Institution, Woods Hole, Massachusetts \\ JOHN MARSHALL AND RAFFAELE FERRARI \\ Department of Earth, Atmosphere and Planetary Sciences, Massachusetts Institute of Technology, \\ Cambridge, Massachusetts
}

(Manuscript received 27 October 2015, in final form 4 April 2016)

\begin{abstract}
The large-scale middepth circulation and eddy diffusivities in the southeast Pacific Ocean and Scotia Sea sectors between $110^{\circ}$ and $45^{\circ} \mathrm{W}$ of the Antarctic Circumpolar Current (ACC) are described based on a subsurface quasi-isobaric RAFOS-float-based Lagrangian dataset. These RAFOS float data were collected during the Diapycnal and Isopycnal Mixing Experiment in the Southern Ocean (DIMES). The mean flow, adjusted to a common 1400-m depth, shows the presence of jets in the time-averaged sense with speeds of $6 \mathrm{~cm} \mathrm{~s}^{-1}$ in the southeast Pacific Ocean and upward of $13 \mathrm{~cm} \mathrm{~s}^{-1}$ in the Scotia Sea. These jets appear to be locked to topography in the Scotia Sea but, aside from negotiating a seamount chain, are mostly free of local topographic constraints in the southeast Pacific Ocean. The eddy kinetic energy (EKE) is higher than the mean kinetic energy everywhere in the sampled domain by about $50 \%$. The magnitude of the EKE increases drastically (by a factor of 2 or more) as the current crosses over the Hero and Shackleton fracture zones into the Scotia Sea. The meridional isopycnal stirring shows lateral and vertical variations with local eddy diffusivities as high as $2800 \pm 600 \mathrm{~m}^{2} \mathrm{~s}^{-1}$ at $700 \mathrm{~m}$ decreasing to $990 \pm 200 \mathrm{~m}^{2} \mathrm{~s}^{-1}$ at $1800 \mathrm{~m}$ in the southeast Pacific Ocean. However, the cross-ACC diffusivity in the southeast Pacific Ocean is significantly lower, with values of $690 \pm 150$ and $1000 \pm 200 \mathrm{~m}^{2} \mathrm{~s}^{-1}$ at shallow and deep levels, respectively, due to the action of jets. The crossACC diffusivity in the Scotia Sea is about $1200 \pm 500 \mathrm{~m}^{2} \mathrm{~s}^{-1}$.
\end{abstract}

\section{Introduction}

The global ocean circulation is often divided into a nearly horizontal, or approximately isopycnal, component

${ }^{\mathrm{a}}$ Geophysical Fluid Dynamics Institute Contribution Number 476.

Corresponding author address: Dhruv Balwada, Geophysical Fluid Dynamics Institute, Florida State University, 018 Keen Building, 77 Chieftan Way, Tallahassee, FL 32306-4360.

E-mail: db10d@fsu.edu and an overturning component that is more tightly linked to diabatic processes in the interior or at the polar extremes. The polar extremes of dense water formation create water masses that spread and fill the global ocean, but this spreading depends on the topography of ocean basins. The cold deep water formed in the northern polar regions of the Atlantic Ocean, North Atlantic Deep Water (NADW), flows south in a deep western boundary current and eventually spreads along the northern flank of the Antarctic Circumpolar Current (ACC) on its course to the Indian and Pacific Ocean 
basins. A fraction of NADW is injected into the ACC in layers below the Drake Passage sill depth and can be transported across the ACC in deep geostrophic boundary currents to upwell into regions of surface buoyancy loss and to be transformed into Antarctic Bottom Water (AABW). This AABW and the other part of the NADW that moves into the Indian and Pacific basins are transformed to Indian Ocean Deep Water (IDW) and Pacific Ocean Deep Water (PDW) via diapycnal processes (e.g., Talley 2013).

The shallower portions of these deep water masses of the Indian and Pacific Oceans, referred to as Upper Circumpolar Deep Waters (UCDW), form layers in the Drake Passage latitude band that are above the sill depth, sill depth being a somewhat complicated construct primarily due to the Scotia Arc and the Kerguelen Plateau. In these layers, simple theory suggests that there is no mean geostrophic flow across the $500-\mathrm{km}$ band of the ACC (Warren 1990). It is often argued that the dynamics in these layers is like that of the atmosphere, where the action of eddies can produce a mean residual flux that on large scales in the Southern Ocean is toward the south (Thompson 2008). To quantify the transport of this residual flux, in the absence of accurate deep velocity measurements, one needs to quantify the amplitude of the isopycnal eddy stirring (eddy diffusivity) and the large-scale gradient of thickness or potential vorticity (PV). Indirect estimates with box model inversions suggest a southward flux of order $10 \mathrm{~Sv}(1 \mathrm{~Sv} \equiv$ $10^{6} \mathrm{~m}^{3} \mathrm{~s}^{-1}$ ) in deep layers (Lumpkin and Speer 2007; Sloyan and Rintoul 2001; Naveira Garabato et al. 2014).

One view of the ACC (Meredith et al.2011) is that of a large-scale, latitudinally broad mean eastward flow, with a transport of about $140 \mathrm{~Sv}$. However, there are large meridional excursions in the regions where it goes over midocean ridges and approaches continents. On this broad, baroclinically unstable mean flow lays a convoluted structure of jets and eddies (Sokolov and Rintoul 2009). The merging and splitting can at any instance be acting as a barrier to mixing and at another instance strongly mix fluid parcels (Thompson 2010). This is in marked contrast to the Gulf Stream, for example, where a single primary jet exists. The ACC jets can be locked to topography, and nearly stationary, or more freely evolving typically in regions with less topographic control (Sallée et al. 2008a).

Although the importance of the ACC to the adiabatic closure of the meridional overturning circulation has been inferred for some time, direct measurements of the strength and nature of this process have been lacking (Marshall and Speer 2012). Here we analyze results from an observational campaign, Diapycnal and Isopycnal Mixing Experiment in the Southern Ocean (DIMES), which was undertaken in 2009-14 to quantify the magnitude of isopycnal eddy diffusivities and diapycnal mixing. We present results from the deployment of RAFOS floats (subsurface drifters tracked by a moored acoustic network) in the southeast Pacific Ocean and Scotia Sea sectors of the ACC. We focus here on velocity statistics (section 3) and isopycnal mixing (section 4) derived from the RAFOS float observations.

\section{Overview of the DIMES RAFOS float experiment}

RAFOS floats were deployed as part of the DIMES experiment, primarily between the synoptically observed positions of the Subantarctic Front (SAF) and Polar Front (PF) at $105^{\circ} \mathrm{W}$. Additional floats were deployed downstream of this deployment site to supplement the dataset. The total number of floats deployed was 210 . However, after failures, 140 float tracks comprising 183 years of float data (66795 float days) were retrieved. Figure 1 shows a summary of the experimental design and regional geography, together with the mean sea surface height ( $\mathrm{SSH}$ ) contour lines that envelope the extent of the initial float deployment relative to the ACC and the climatological position of the SAF and PF according to Orsi et al. (1995). These SSH and frontal positions provide a general sense of the largescale ACC flow in the region that was sampled.

The duration of the RAFOS float experiment was from 2009 to 2011, with the highest number of float days sampled in 2010 (Fig. 2). The floats were originally ballasted to stay near two isopycnal surfaces of neutral density 27.6 and $27.9 \sigma$. However, because of technical failures, the behavior was closer to that of isobaric floats. For this reason, the analysis in this manuscript treats the floats as quasi-isobaric floats. Some floats showed a slow sinking of about $100 \mathrm{~m} \mathrm{yr}^{-1}$, which does not affect any results presented here. The distribution of float days in depth shows a bimodal structure with peaks at 800 and $1400 \mathrm{~m}$ corresponding to the mean positions of the ballasting isopycnals. As the floats did not maintain their target density, the float days distribution in temperature is wider, showing only a single peak. A distribution of float days over topographic depth following the float shows a peak at $4500 \mathrm{~m}$ corresponding to the mean depth of the southeast Pacific Ocean. This distribution also has a long tail toward shallower depths corresponding to the passage through the Scotia Sea, where topographic variability is greater and topographic features often reach within a few hundred meters of the surface. Hancock and Speer (2013a,b) provide a detailed report of this dataset.

The float trajectories clearly show a great deal of complexity, both at shallow and deep depth ranges, 


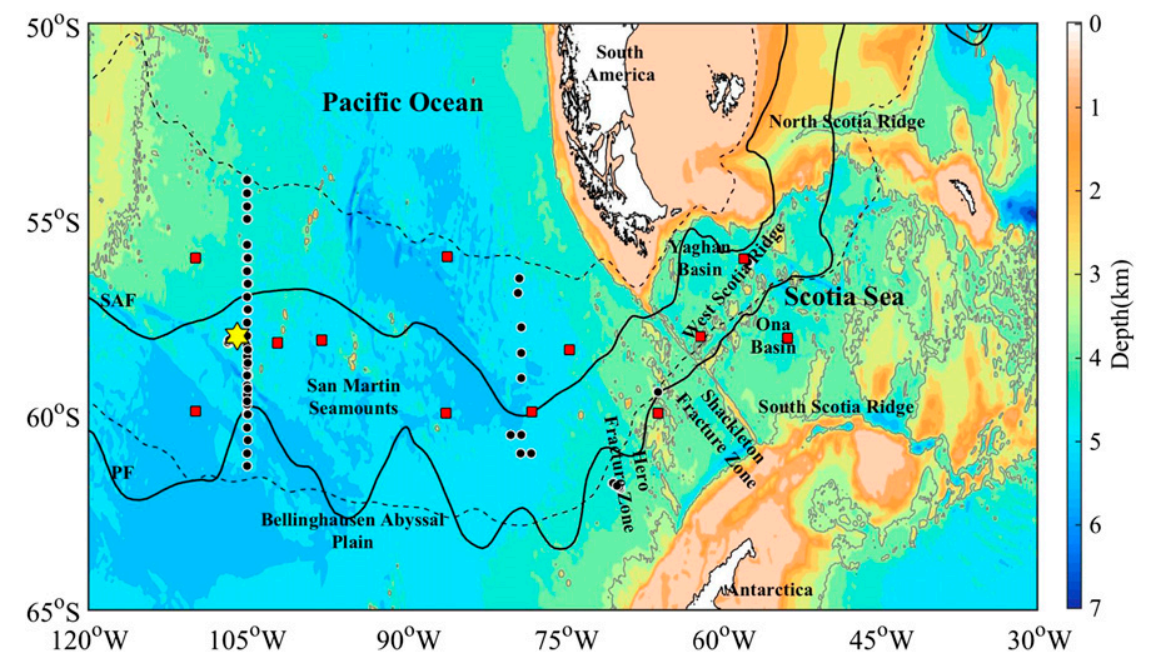

FIG. 1. Regional geography with the major topographic features (bathymetry colored with contour spacing of $500 \mathrm{~m}$ ) and experimental components. The 0 - and 3300-m depth contours are displayed in black and gray, respectively, to highlight the major topographic features. The yellow star is the tracer deployment location, the black dots are the float deployment locations, and the red squares are the positions of the sound sources. SSH contours $(-60$ and $20 \mathrm{~cm}$, dashed lines), which engulf the initial float deployment locations, highlight the position of the ACC through the region. SAF and PF (solid black lines) from Orsi et al. (1995).

created by the mesoscale eddies and presence of vertical shear, the latter apparent from the longer displacements of the shallower floats (Fig. 3). Even though many floats were deployed north of the historical position of the SAF, all floats proceeded east and exited the southeast Pacific Ocean; remarkably, none moved northward sufficiently to be trapped and subsequently circulate in the subtropical gyre of the Pacific Ocean. This behavior is in agreement with the circulation found by Faure and Speer (2012), who show the presence of a mean flow toward the ACC in the middepth layers between 1000 and $3000 \mathrm{~m}$. In contrast, on the southern side of the ACC, a number of floats did appear to be continuing to move south, away from the core of the ACC.

The concentration of floats, or density in float days, is highest near and just downstream of the deployment site at $105^{\circ} \mathrm{W}$; a secondary peak is seen near the downstream deployment at $75^{\circ} \mathrm{W}$ (Fig. 4, top). This float density figure is akin to a coarse-resolution map of tracer spreading from a permanent tracer source located at float deployment location (Ollitrault and Colin de Verdière 2002), but more importantly it provides a sense of the statistical accuracy that can be expected for the results presented here. A second representation of the float density is provided (Fig. 4, bottom), showing the number of floats passing through each longitudinal section summed in meridional bins and then normalized by the total number of floats that pass through that longitudinal section. This effectively renormalizes the concentration as the float cluster evolves downstream.
A qualitative sense of the ACC flow, the transport pathways, and its prominent features during the experiment emerges from the tracks (Fig. 3) and the geographically binned (Eulerian) displays (Fig. 4, bottom; see also section 3 ). One of these is a large meander at $59^{\circ} \mathrm{S}, 100^{\circ} \mathrm{W}$, which was experienced by the floats in both the 2009 and 2010 deployments. This meander splits into two jets at $95^{\circ} \mathrm{W}$, presumably upon interacting with the San Martin seamounts. We speculate that one of these jets is associated with the PF and the other with the SAF. The jets merge as they approach Drake Passage, cross barotropic PV $(f / H)$ contours, move northward, and make their way over the northern ends of the Hero and Shackleton fracture zones through deep troughs, into the Yaghan basin. Once in the Yaghan basin, the floats are again divided into two groups following topographic contours of the continental slope on the northern side and the West Scotia Ridge on the southern side of the Yaghan basin. They exit the Scotia Sea through the openings in the North Scotia Ridge, beyond which tracking becomes problematic as the topography blocks most of the sound source signals.

Along with the float data, SSH estimates were also used in this study for an approximate streamfunction and for surface geostrophic velocities. These data were obtained as absolute dynamic topography (ADT) data, an altimeter product produced by Ssalto/Duacs and distributed by AVISO, with support from CNES (http:/ www.aviso.altimetry.fr/duacs/). 

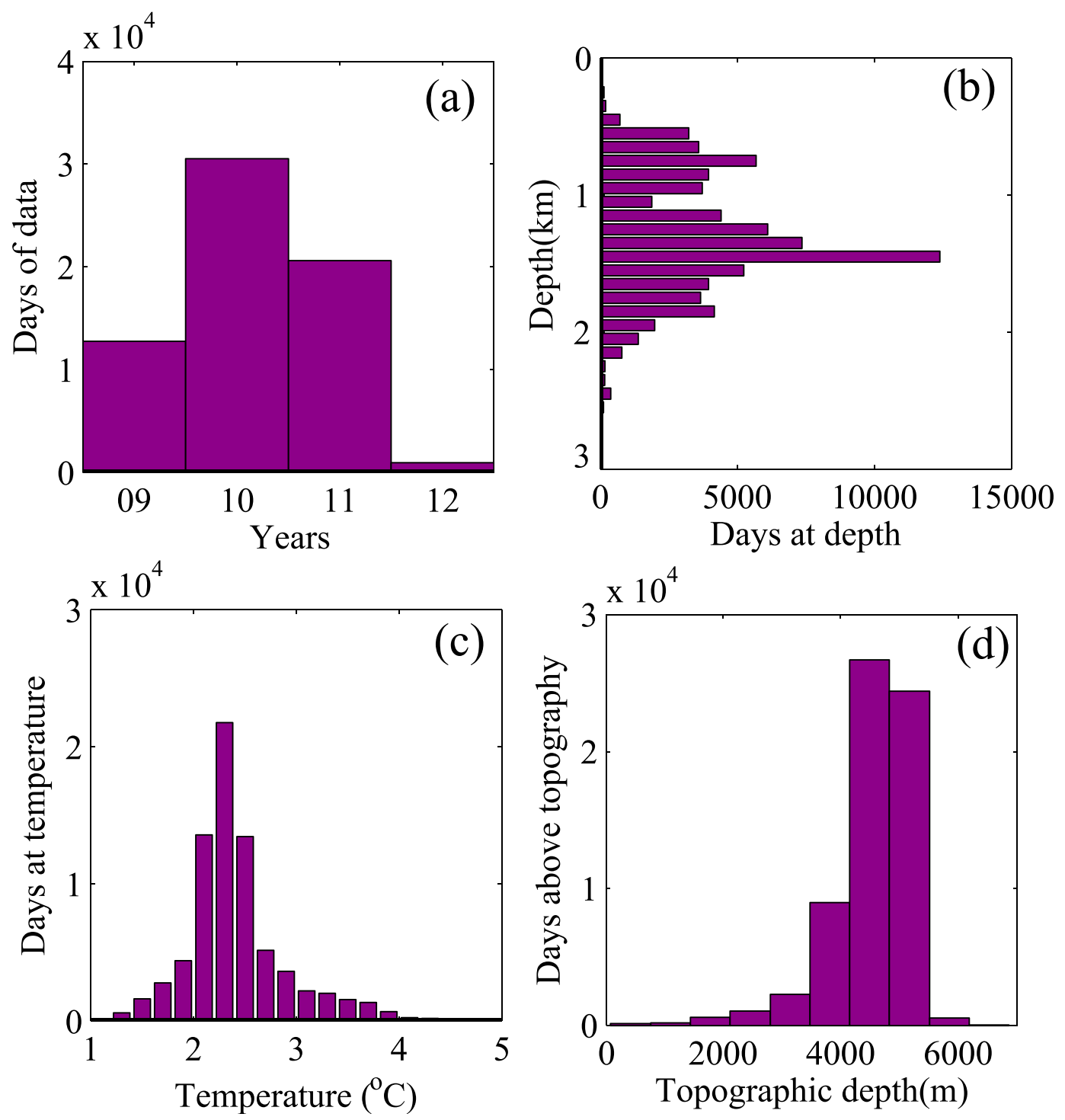

FIG. 2. Distribution of the total float days as a function of (a) calendar year, (b) pressure, (c) temperature, and (d) height above topography.

\section{Eulerian mean flow}

\section{a. Vertical structure of flow}

In this section, we first present a comparison of float velocities to SSH-derived velocities and later present vertical profiles of velocities averaged over large basin scales (southeast Pacific Ocean and Scotia Sea). It is important to note that the comparison of float velocities to SSH velocities should not be expected to be highly accurate because of resolution limitations of the AVISO altimeter. The SSH fields are available in 7-day averaged fields, which are then used to calculate the surface geostrophic velocities from the geostrophic streamfunction $\psi=g \eta / f$, where $g$ is the gravitational acceleration, $f$ is the Coriolis frequency, and $\eta$ is the SSH. The float velocities, resolved daily, are smoothed using a running mean with an averaging window of 7 days for comparison against the SSH-derived fields. However, the results of this section were found to not be sensitive to the size of the smoothing window (not shown).

We calculate the ratio of the float speed to the SSHderived speed and the angle $(\theta)$ between the two velocities. These are then binned in depth bins for each of the basins (southeast Pacific Ocean and Scotia Sea) and plotted in Fig. 5. The modal depth structure is similar to a decaying exponential, which agrees with the expectations based on previous studies describing 

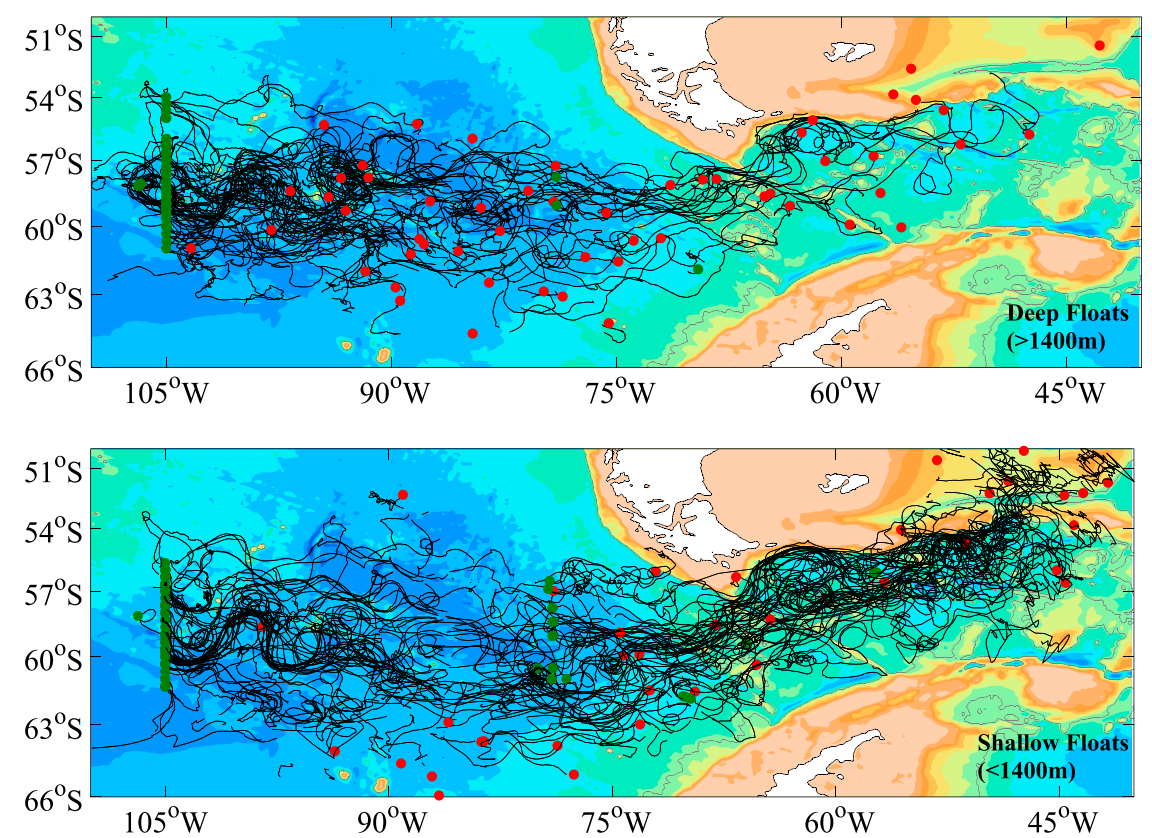

FIG. 3. Trajectories of the floats with mean depth (top) greater than $1400 \mathrm{~m}$ (60 tracks) and (bottom) shallower than $1400 \mathrm{~m}$ ( 80 tracks). The green dots represent the launch locations and the red dots represent the surfacing locations.

the equivalent barotropic (EB) nature of the ACC (Killworth 1992; Hughes and Killworth 1995; LaCasce and Isachsen 2010).

The $e$-folding scale of the mode of the ratio is approximately $1650 \mathrm{~m}$ in the southeast Pacific Ocean and $1300 \mathrm{~m}$ in the Scotia Sea. Chereskin et al. (2010) suggest an $e$-folding scale of $1900 \mathrm{~m}$ in the southeast Pacific Ocean. Firing et al. (2011) showed that the $e$-folding scale varies between 1100 and $1700 \mathrm{~m}$ in the Drake Passage as calculated from the Southern Ocean state estimate (SOSE; Mazloff et al. 2010). However, the results from their shipboard ADCP measurements, which
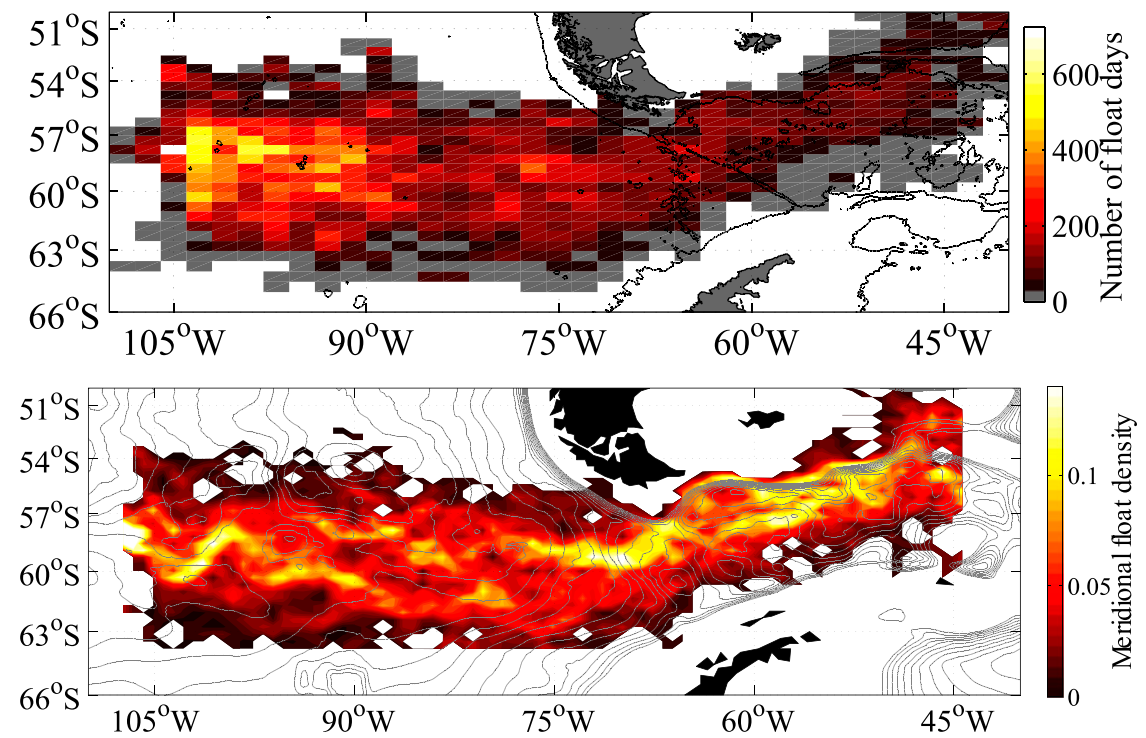

FIG. 4. (top) Number of float days in $2.0^{\circ} \times 0.5^{\circ}$ bins, chosen to be the same as the bin size used for calculating horizontal structure of mean flow. (bottom) A contour map of number of floats that cross through a meridional bin normalized by the total number of floats that cross through the corresponding meridian. Barotropic PV $(f / H)$ contours are shown in gray. 


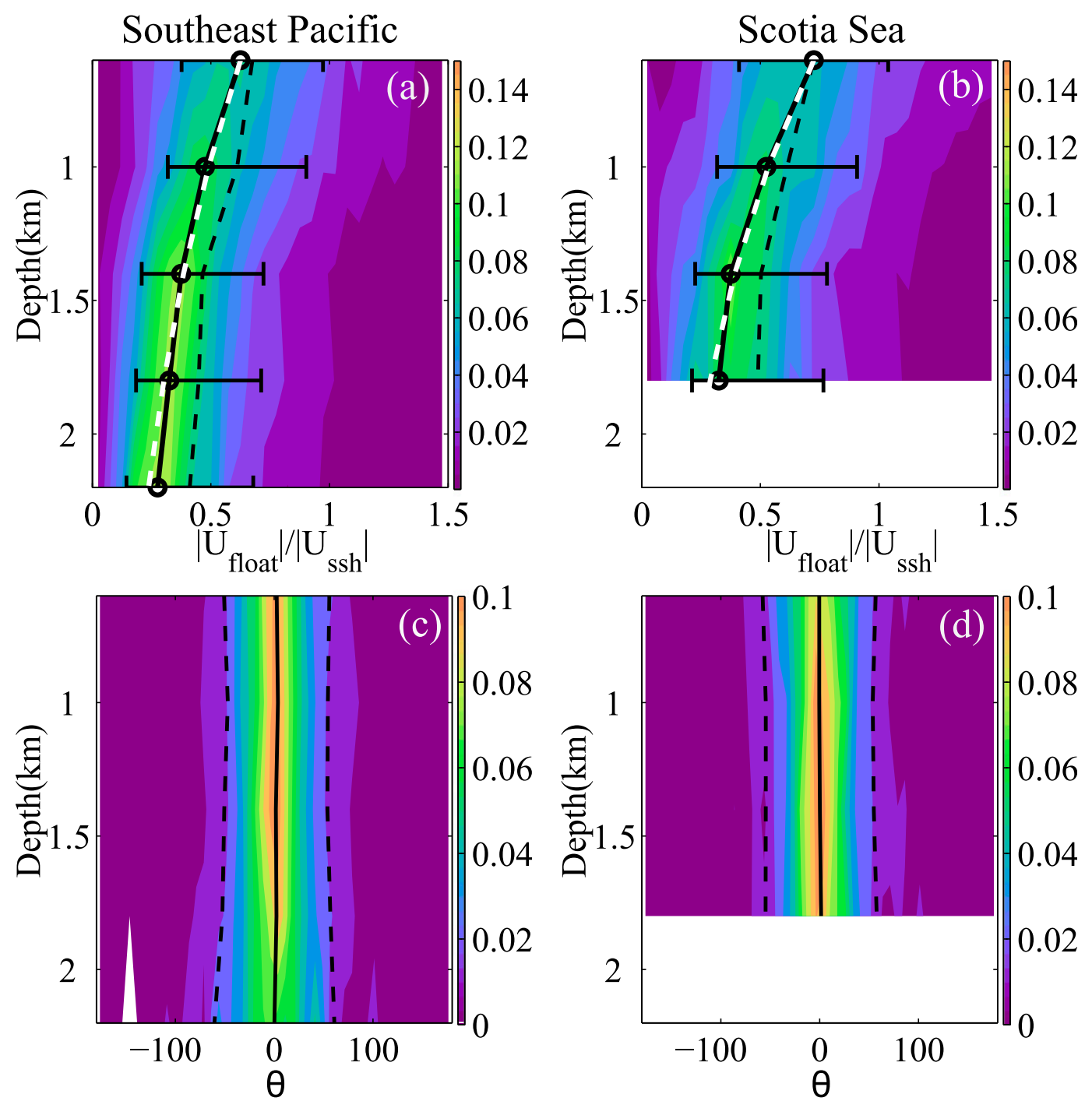

FIG. 5. (top) Geostrophic velocities, calculated using SSH, compared with velocities from the floats. Probability distribution functions of ratio of float speed vs SSH-derived speed plotted vs depth for (a) southeast Pacific Ocean and (b) Scotia Sea. Mode (solid lines) and mean (dashed black lines) are given, and error bars represent one standard deviation; exponential fits (dashed white lines) with depth scales of $1300 \mathrm{~m}$ in the Scotia Sea and $1650 \mathrm{~m}$ in the southeast Pacific Ocean are also shown. (bottom) PDF of the angle between SSH-derived velocity and float velocity as a function of depth for (c) the southeast Pacific Ocean and (d) Scotia Sea; solid black line represents mean and dashed black line represents one standard deviation.

sampled from the surface to $1000 \mathrm{~m}$, were less clear and could not distinguish between the profile being linear or exponential. Lack of a perfect match to previous estimates is a result of both the time variability of the current and also the shoaling of the thermocline to the south leading to spatial variability and time variability of the $e$-folding scale (Karsten and Marshall 2002). The probability distribution function (PDF) of angle between surface and float velocities versus depth has a mean of zero and a standard deviation around $50^{\circ}-55^{\circ}$ for almost all bins.
The EB nature of the ACC was discussed in a dynamical setting by Hughes and Killworth (1995). They showed that for a linear geostrophic flow in the interior (away from influence of wind stress) the turning of the velocity vector with depth took the form

$$
\phi_{z}=-\frac{N^{2} w}{f|u|^{2}}
$$

where $N^{2}$ is the usual Brunt-Väisälä frequency, $w$ is the vertical velocity, $f$ is the Coriolis force, $|u|$ is the flow 


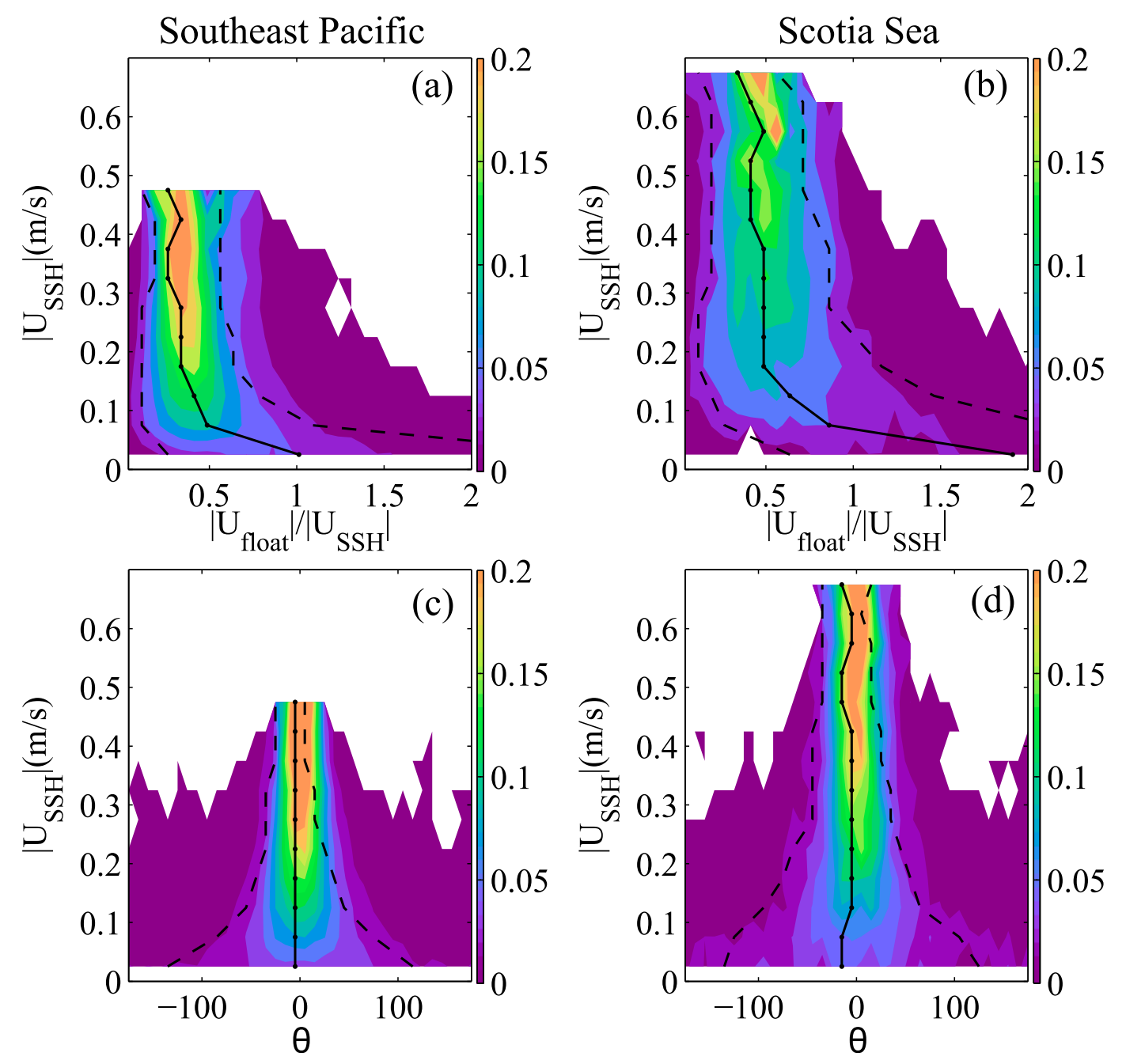

FIG. 6. (top) PDF of the ratio of float speed to SSH-derived geostrophic speed binned in surface speed bins for (a) the southeast Pacific Ocean and (b) Scotia Sea. (bottom) PDF of angle between SSH-derived velocity and float velocity binned in surface speed bins for (c) southeast Pacific Ocean and (d) Scotia Sea. Solid black lines represent means and dashed black lines represent one standard deviation.

speed, and $\phi_{z}$ is the variation of angle with depth. This formula holds on scales that are large enough for the Rossby number to be small. It shows that, for regions of weak vertical flow (slowly varying topography), weak stratification, and strong horizontal flows, the turning with depth will be small. We reiterate that the ACC also has a weaker stratification and stronger horizontal flows compared to other strong currents, which are probably the primary contributors to the EB nature in the ACC. Previous observational studies in the ACC (Phillips and Bindoff 2014; Ferrari et al. 2012) have shown some broad consistency with relation (1), showing vertical coherence and small turning of velocity vectors with depth, the turning increasing in regions of strong cross-topographic flows, where large vertical velocities would be expected.

Ratios and angles between the float and SSH-derived velocities are binned as a function of surface speed (Fig. 6). Both the ratios and the angles $\left(\theta \approx \phi_{z} h\right.$, where $h$ is the depth) are more variable for slower surface speeds than faster surface speeds. The increased turning of the floats with slower speeds is in agreement with relation (1) discussed above. One might also expect there to be more turning in the Scotia Sea relative to the southeast Pacific because of stronger vertical velocities being generated by rougher topography (Hughes 2005; Thompson and Naveira Garabato 2014; note the topographic features in Fig. 1), and there is some evidence for this difference (Figs. 6c,d). However it is important 
to point out that the slower surface speeds (specially below $0.1 \mathrm{~m} \mathrm{~s}^{-1}$ ) are associated with a greater mean velocity ratio, and more variability of the ratio and angle between float speed to surface speed can be a result of errors associated with the altimeter SSH measurement. To resolve flows with a surface speed of $0.1 \mathrm{~m} \mathrm{~s}^{-1}$, the SSH changes need to be resolved with an accuracy of $2.5 \mathrm{~cm}$ over a length scale of $25 \mathrm{~km}$ (using the relation $\psi=g \eta / f)$. This is below the accuracy limit on most altimeters; for example, Ocean Surface Topography Mission (OSTM)/Jason-2 sensors have an accuracy of about $3.3 \mathrm{~cm}$. We conclude that there is an indication of more turning with depth and non-EB behavior in the Scotia Sea versus the southeast Pacific, but because of large errors this result is not entirely conclusive.

Vertical structure of basin-averaged velocities and their associated eddy kinetic energy (EKE; Fig. 7) were computed using the raw velocities with no filtering, in contrast to what was done previously to compare to $\mathrm{SSH}$. The mean zonal velocity decreases from a value of $6 \mathrm{~cm} \mathrm{~s}^{-1}$ at $600 \mathrm{~m}$ to close to $1 \mathrm{~cm} \mathrm{~s}^{-1}$ at $2400 \mathrm{~m}$ in the southeast Pacific Ocean. The mean meridional velocity is close to zero $\left(<1 \mathrm{~cm} \mathrm{~s}^{-1}\right)$ but with a slight southward flow component, associated with the southeastward ACC flow in this region. The EKE in the southeast Pacific Ocean shows a decrease with depth, dropping from a value of 80 to $20 \mathrm{~cm}^{2} \mathrm{~s}^{-2}$. The zonal and meridional EKE have a similar structure in the vertical, with a slightly higher meridional EKE. The Scotia Sea has a velocity profile that shows higher magnitudes of mean speed and velocity variance than the southeast Pacific Ocean sector and also decreases with depth. The mean zonal velocity decreases from $10 \mathrm{~cm} \mathrm{~s}^{-1}$ at $400 \mathrm{~m}$ to $5 \mathrm{~cm} \mathrm{~s}^{-1}$ at $1800 \mathrm{~m}$. The mean meridional velocity is positive as the ACC flows north with speeds of $6 \mathrm{~cm} \mathrm{~s}^{-1}$ near $400 \mathrm{~m}$ decreasing to $1 \mathrm{~cm} \mathrm{~s}^{-1}$ at $1800 \mathrm{~m}$. The EKE are similar, with slightly higher zonal EKE, in the zonal and meridional directions, from $250 \mathrm{~cm}^{2} \mathrm{~s}^{-2}$ at $400 \mathrm{~m}$ to $60 \mathrm{~cm}^{2} \mathrm{~s}^{-2}$ at $1800 \mathrm{~m}$. The EKE in both the southeast Pacific Ocean and Scotia Sea decrease rapidly up to about $1300 \mathrm{~m}$, and then the decrease becomes more gradual. Also, in both the regions the energy of the mean flow is smaller than the EKE. A comparison of these results to those of fixed current meter estimates is provided at the end of this section.

\section{b. Horizontal structure of flow}

The mean flow was estimated by binning the float velocities into $2.0^{\circ}$ zonal $\times 0.5^{\circ}$ meridional bins. This choice was made based on the knowledge that the structures present in the mean flow, such as jets, have greater meridional spatial variability. The size of the bins was chosen such that the bins were large enough to
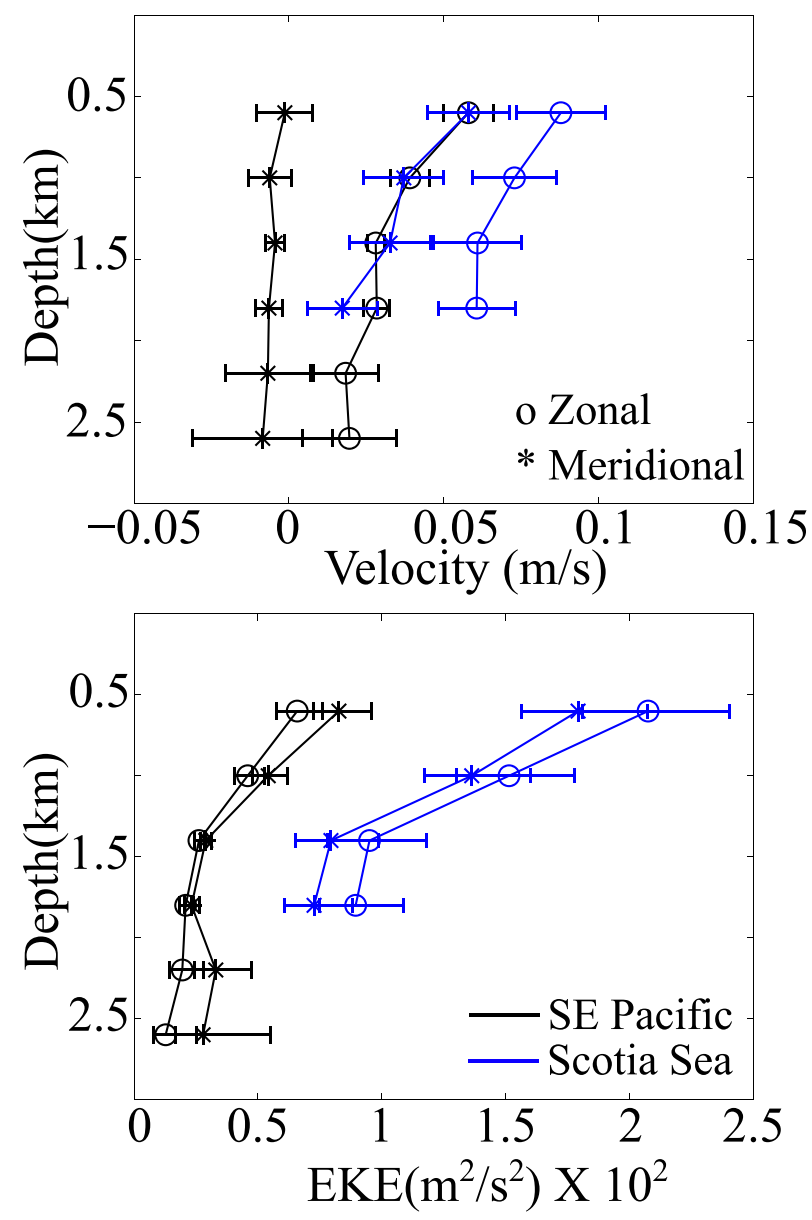

FIG. 7. (top) Vertical structure of mean velocity in the southeast Pacific Ocean (black) and Scotia Sea (blue). (bottom) EKE in the southeast Pacific Ocean (black) and Scotia Sea (blue) binned in depth level bins. Circles and stars represent the zonal and meridional components, respectively.

encompass a sufficient number of data samples but also small enough to resolve the flow structures that are present in the mean flow. It is important to recognize that the variability or EKE estimates in each bin reflect not only the time variable component but also the mean horizontal shear that might be present in the region covered by the bin. As the floats were spread unevenly in the vertical in each bin, an adjustment/rescaling was done to the horizontal velocities to approximate the corresponding velocity at the $1400-\mathrm{m}$ depth level (this is the level where the highest number of float days was sampled). This adjustment was done assuming an EB structure and using the mean speed vertical profile in each of the basins, calculated using all the float velocities (separately for the southeast Pacific Ocean and Scotia Sea). Adopting this rescaling approach ensured more statistical reliability based on the results shown in the previous subsection. 

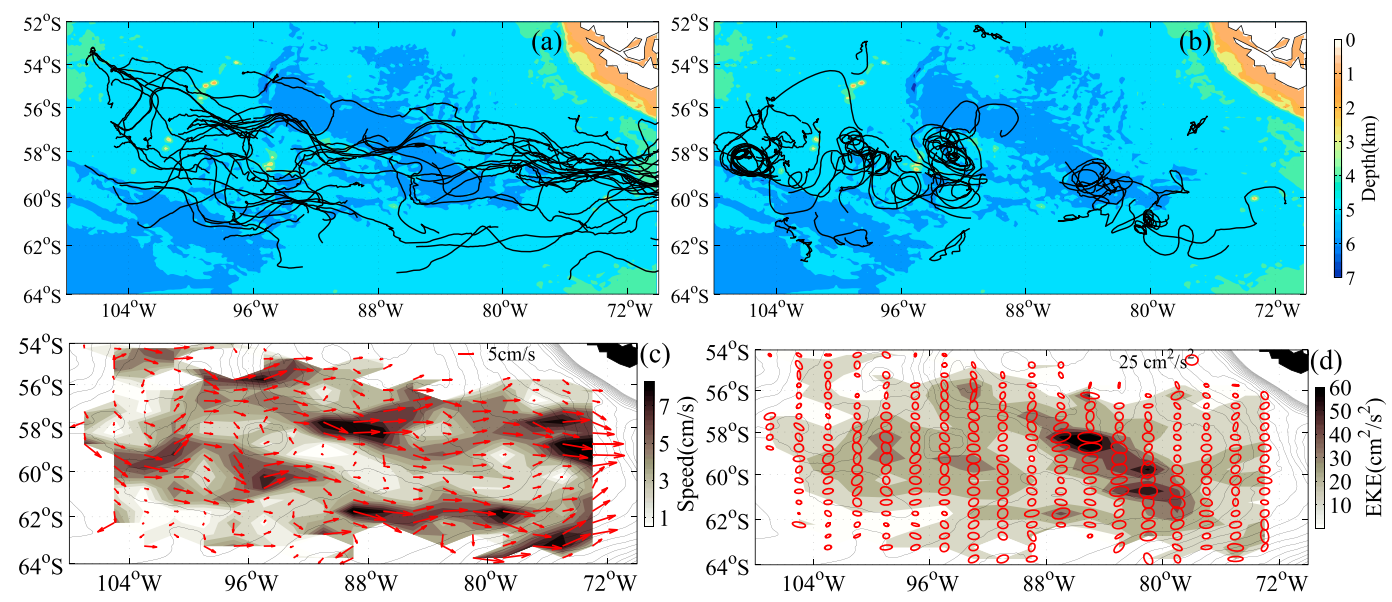

FIG. 8. (top) Float tracks in the southeast Pacific Ocean, showing (a) straight and (b) looping tracks. Depth is contoured in color. (bottom) Binned Eulerian fields for the southeast Pacific Ocean. (c) Arrows indicate direction, mean speed is shaded. (d) EKE along with standard deviation ellipses. Barotropic PV $(f / H)$ contours are shown (solid lines).

To emphasize the relation between the averaged data and the underlying trajectories, we also present selected trajectory segments, chosen as follows. The float tracks were subdivided into 120-day segments, and then for each segment the ratio $(\varepsilon)$ of float displacement to the total distance was calculated as

$$
\varepsilon=\frac{\int_{0}^{120} \mathbf{u} d t}{\int_{0}^{120}|\mathbf{u}| d t},
$$

where $\mathbf{u}$ is the velocity of the float and $|\cdot|$ represents the absolute value. This ratio is always less than or equal to 1 ; for a straight line the ratio is 1 and for a full circle it is zero. This ratio was used to group the tracks into looping and other, nonlooping segments.

In the southeast Pacific Ocean there are three primary regions where looping is found (Fig. 8, top). The first one is a single large eddy near the deployment line $\left(105^{\circ} \mathrm{W}\right)$ in which many floats were deployed. The second location is both upstream and downstream of the San Martin seamounts. The upstream location is associated with the crest of the large meander where the flow appears to split into smaller eddies, and the downstream location is associated with larger loops. The third region of looping is found around $60^{\circ} \mathrm{S}, 85^{\circ} \mathrm{W}$. The straighter float tracks lie in regions of time mean jets, as seen in Eulerian means discussed below, which are located on the northern and southern sides of the looping regions. In the Scotia Sea the strong recirculation of the Yaghan basin stands out (Fig. 9, top). There is another looping area where the EKE increases for the second time downstream of the Yaghan basin. The straighter trajectories appear to trace out the continental slope and West Scotia Ridge, similar to the strong mean flows discussed below.

The binned mean velocity field in the southeast Pacific Ocean (Fig. 8, bottom) shows primarily an eastward zonal flow in two principal jets spaced approximately $200 \mathrm{~km}$ apart, with a small southward component. The maximum bin-averaged speeds at $1400 \mathrm{~m}$ are approximately $6-8 \mathrm{~cm} \mathrm{~s}^{-1}$ in the core of the jets. We identified these jets as the SAF and PF based on the hydrographic properties associated with strong flows that were observed during the deployment cruises (not shown). The PF shows a meander in the binned mean flow upstream of the San Martin seamounts at $59^{\circ} \mathrm{S}, 95^{\circ} \mathrm{W}$, which seems to be associated with the barotropic $\mathrm{PV}(f / H)$. This is probably the reason for the repeated appearance of the large meander at this location, as may be seen in Hovmöller plots of SSH (not shown) and by the two float deployments. The San Martin seamounts at $59^{\circ} \mathrm{S}, 95^{\circ} \mathrm{W}$ are associated with a weaker mean flow, extending downstream of the seamounts.

The meandering of the jets upstream of the San Martin seamounts is associated with a slightly higher EKE. The northern jet flows along $f / H$ contours near $57^{\circ} \mathrm{S}, 90^{\circ} \mathrm{W}$ and weakens downstream where the $f / H$ contours diverge. This divergence of $f / H$ contours is collocated with a tongue of high EKE- the highest in the southeast Pacific Ocean-that is also one of the regions where large looping is seen. The standard deviation ellipses in this region are primarily isotropic, with a slightly greater zonal component associated with the region where the highest EKE is observed in the region. 

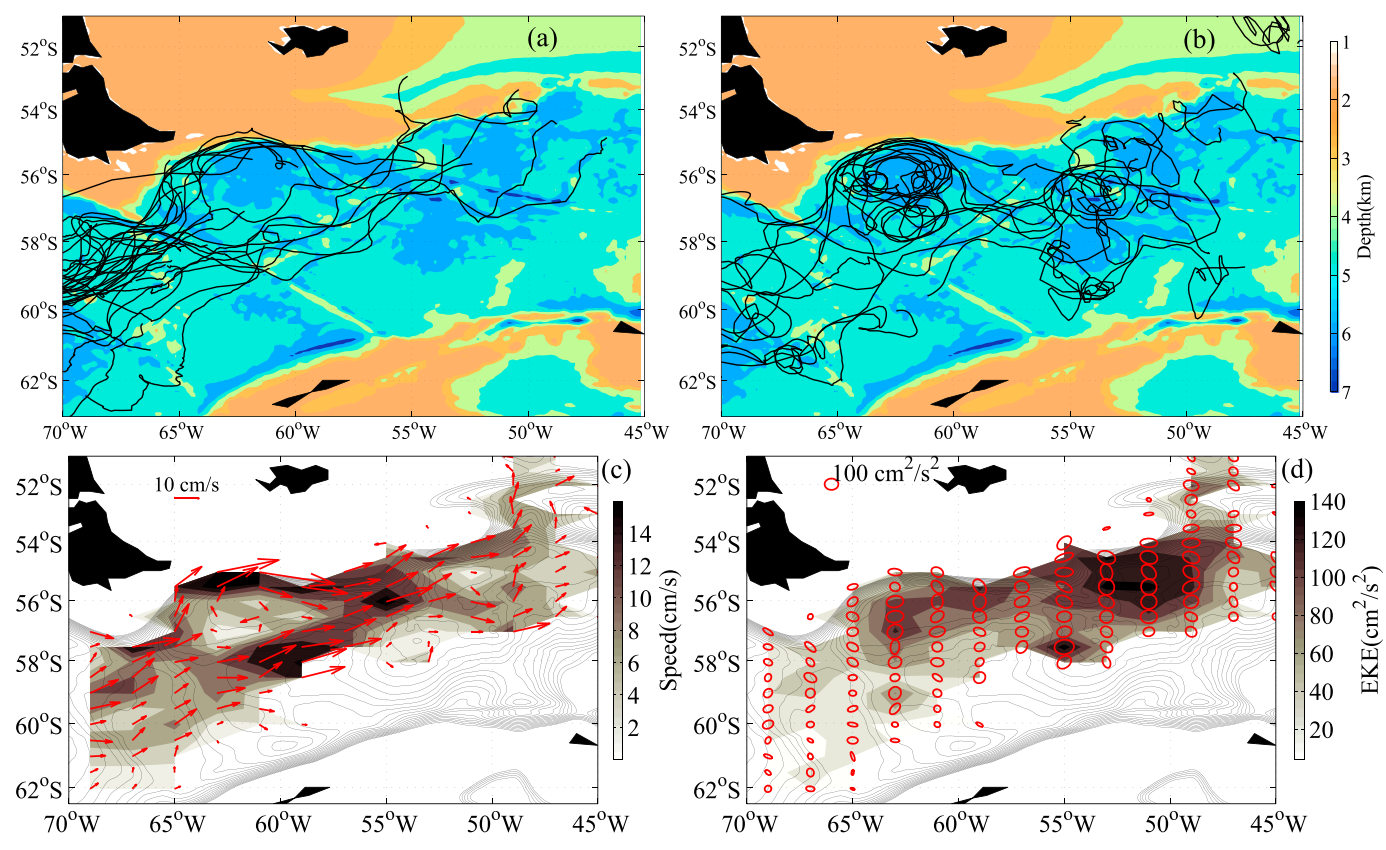

FIG. 9. As in Fig. 8, but for the Scotia Sea.

In the Scotia Sea (Fig. 9, bottom), the strongest average speeds near the $1400-\mathrm{m}$ level are $14-16 \mathrm{~cm} \mathrm{~s}^{-1}$, twice that of the southeast Pacific Ocean. The mean velocity vectors in this region have a northward component associated with the ACC turning north and crossing over the North Scotia Ridge. The velocity shows the ACC approaching the Shackleton fracture zone as a single broad jet, with the strongest flows located near the northern side of the Drake Passage. This jet splits into two branches as it crosses the Shackleton fracture zone. The northern branch closely hugs the continental slope of South America, like a boundary current, and the southern branch goes south of the Yaghan basin over the West Scotia Ridge. A strong cyclonic recirculation is associated with the topographic depression in the Yaghan basin, as the mean velocity vectors turn westward in the center of the basin. The segments of the trajectories shown in Fig. 9 also showed the presence of a recirculation in this region.

High EKE is evident downstream of the Hero and Shackleton fracture zones in the Yaghan basin (Fig. 12). This increase in EKE is probably associated with instabilities related to the crossing of two fracture zones and the time variability of the Yaghan basin topographic recirculation. The highest EKE signal in the Scotia Sea is found near $56^{\circ} \mathrm{S}, 51^{\circ} \mathrm{W}$. This is downstream of the region where the two topographic jets merge and possibly interact with a topographic bump located at $55^{\circ} \mathrm{S}$, $54^{\circ} \mathrm{W}$. This region also shows significant looping in the trajectories. The standard deviation ellipses, similar to the Pacific Ocean sector, do not have a strong preferred orientation except in some bins near the boundaries, where they are oriented zonally along the topography.

\section{c. Comparison to previous flow estimates}

Previous flow measurements in the region sampled here can be divided into four broad categories: current meter mooring experiments (Sciremammano et al. 1980; Ferrari et al. 2012, 2013), synoptic sampling of flow by ADCP measurements from ships (Lenn et al. 2007; Chereskin et al. 2010; Firing et al. 2011), analysis of SSHderived flow fields (Barré et al. 2011), and coarseresolution float-derived means (Gille 2003a,b). Each method of flow measurement, including the Lagrangian analysis provided in this study, has advantages and disadvantages. The Lagrangian analysis provided here has the advantage that it can provide a wealth of information about the spatial structure of the flow over a large region, thus providing a representation of the spatial structure and a sense of the connections by the mean flow between different regions. It is important to realize that a direct comparison of Lagrangian data averaged over a large region (basin average) to those of a current meter collecting data at a specific location will not necessarily provide an exact match. This is because, in a large area average, the Lagrangian instruments average over different flow features and, accounting for flow reversals and recirculation, the mean flow is expected to be slower than the estimate that would be observed by a fixed current meter. Also, the estimate of 
EKE in this large area average would be a measure of both the temporal variability and spatial structure of the flow.

In a qualitative sense, our vertical profiles of velocity and EKE are nevertheless comparable to the current meters at Drake Passage (Sciremammano et al. 1980; Ferrari et al. 2012, 2013). The current meters show mean velocities on the order of $5-40 \mathrm{~cm} \mathrm{~s}^{-1}$ at $500 \mathrm{~m} \mathrm{de}$ creasing to $2-10 \mathrm{~cm} \mathrm{~s}^{-1}$ at $2000 \mathrm{~m}$, where the variation evidently is due to the range of features associated with spatial locations sampled by the current meters. Also, the vertical structure of EKE compares well with the estimates of the variability from current meters. The slight preference for zonal variability over meridional as seen on a large scale in the Scotia Sea (Fig. 7, bottom) and in the velocity ellipses, especially near topography (Fig. 9), has also been seen in current meters that were situated near topographic features. For example, the large cyclonic circulation resident in the Yaghan basin was previously observed in current meter and SSH fields (Ferrari et al. 2012). Lenn et al. (2007) and Firing et al. (2011) noted the permanence of a jet-like feature, associated with the SAF, near the continental slope of South America and a slightly more variable jet associated with the PF passing over the West Scotia Ridge. Chereskin et al. (2010), using estimates of the quasisynoptic flow field in the southeast Pacific Ocean from two observational campaigns in 2005 and 2006, indicated the presence of a jet similar to our northern jet in the southeast Pacific sector.

\section{Length scales, time scales, and isopycnal stirring}

For the analysis that follows, we divided the region into six groups, unless otherwise noted, as follows: three divisions in the zonal direction $\left(110^{\circ}-90^{\circ} \mathrm{W}, 90^{\circ}-\right.$ $70^{\circ} \mathrm{W}$, and $70^{\circ}-40^{\circ} \mathrm{W}$ ) and two divisions in depth (500$1400 \mathrm{~m}$ and $1400-2500 \mathrm{~m}$ ). For each division, the mean $\left(U_{i}=\left\langle u_{i}\right\rangle=1 / N \sum u\right)$, where the sum is over all available observations and $N$ is the number of observations, and residual $\left(u_{i}^{\prime}=u_{i}-U_{i}\right)$ velocities were calculated. Subscripts $i$ represent the direction and can take on values of $u$ (zonal) or $v$ (meridional); for example, $u_{u}$ would imply the zonal component of the velocity. In the following, we do not follow the Einstein notation; repeated index does not imply summation. The means and the corresponding variances are presented in Table 1 . The errors were calculated using standard error calculation methods as described by Ollitrault and Colin de Verdière (2002). The Reynolds fluxes (not shown) were calculated and are negligible for such large area averages.

Spatial correlations are calculated as

$$
C_{i i}^{e}(r)=\frac{\left\langle u_{i}^{\prime}(x) u_{i}^{\prime}(\mathbf{x}+r)\right\rangle}{\left\langle u_{i}^{\prime}(\mathbf{x}) u_{i}^{\prime}(\mathbf{x})\right\rangle}
$$

where $r$ is the separation between the floats and the averaging is done in $50-\mathrm{km} r$ bins using samples from float pairs. Correlation $C_{i i}^{e}$ has a structure that is commonly seen in eddying flows, decreasing exponentially followed by a negative lobe (Fig. 10). These spatial correlations are well resolved in the southeast Pacific and the shallow Scotia Sea, but the deep Scotia Sea has large error bars because of the scarcity of data. We interpret the negative lobe as a signature a dipole-like pattern of cyclonic and anticyclonic eddies that are present in an alternating patterns (Chereskin et al. 2010; Barré et al. 2011).

This correlation function was then used to calculate the quasi-Eulerian integral length scale:

$$
L_{i i}^{e}=\int_{0}^{\infty} C_{i i}^{e}(r) d r .
$$

This calculation is done using two methods, as described below, because we cannot integrate observational correlations to infinity, which would also not be effective because of large-scale inhomogeneities in the ocean. A Monte Carlo-like error estimation method is used to calculate errors, which is similar to the ones used before (Sallée et al. 2008b; Garraffo et al. 2001). In this method, 1000 noisy correlation curves are generated using the mean correlation curve and adding the standard error multiplied by a random number between -2 and 2 for each distance bin from a uniform distribution. Note that because the standard errors are small (as can be seen by error bars in Fig. 10), this procedure did not produce correlation coefficients that are very different from the mean. For the first estimate of the integral length scale, these noisy correlation curves are integrated out to the first zero crossing. In the second method, an exponentially decaying cosine function is fit to the noisy correlation curves, and the integral length scale is given by the analytical integral of the functional form. Both methods produce 1000 estimates, corresponding to each noisy correlation curve that was generated. The average of these estimates is taken to be the integral length scale, and the error is represented as one standard deviation of these estimates. The results are shown in Table 1.

The integral length scale provides an estimate of the spatial length scale over which velocities decorrelate. The integral length scales calculated by integrating to the first zero crossing are on the order of $60 \mathrm{~km}$ for most the region. However, the integral length scales calculated by fitting a decaying cosine function vary from $60 \mathrm{~km}$ in the western southeast Pacific Ocean to about $10 \mathrm{~km}$ in 
TABLE 1. Statistics for DIMES RAFOS floats in six longitudinal and depth bins.

\begin{tabular}{|c|c|c|c|c|c|c|}
\hline \multirow{2}{*}{$\begin{array}{l}\text { Longitude bins } \\
\text { Depth bins }\end{array}$} & \multicolumn{2}{|c|}{$110^{\circ}-90^{\circ} \mathrm{W}$} & \multicolumn{2}{|c|}{$90^{\circ}-70^{\circ} \mathrm{W}$} & \multicolumn{2}{|c|}{$70^{\circ}-40^{\circ} \mathrm{W}$} \\
\hline & $500-1400 \mathrm{~m}$ & $1400-3000 \mathrm{~m}$ & $500-1400 \mathrm{~m}$ & $1400-3000 \mathrm{~m}$ & $500-1400 \mathrm{~m}$ & $1400-3000 \mathrm{~m}$ \\
\hline$L_{u u}^{e}(\mathrm{~km})$ & $75.09 \pm 1.17$ & $57.81 \pm 0.79$ & $73.45 \pm 6.1$ & $77.90 \pm 6.64$ & $57.47 \pm 3.16$ & $56.60 \pm 9.62$ \\
\hline$L_{v v}^{e}(\mathrm{~km})$ & $92.03 \pm 1.53$ & $60.97 \pm 0.99$ & $65.59 \pm 2.35$ & $77.11 \pm 8.12$ & $68.49 \pm 5.12$ & $62.22 \pm 16.06$ \\
\hline$L_{u u}^{e}($ fit $)(\mathrm{km})$ & $63.88 \pm 2.03$ & $36.06 \pm 1.11$ & $56.56 \pm 5.19$ & $14.78 \pm 3.91$ & $28.34 \pm 5.29$ & $14.11 \pm 7.91$ \\
\hline$L_{v v}^{e}(\mathrm{fit})(\mathrm{km})$ & $44.40 \pm 2.18$ & $29.96 \pm 0.99$ & $37.63 \pm 5.25$ & $31.80 \pm 4.35$ & $22.33 \pm 3.83$ & $13.8 \pm 5.71$ \\
\hline First zero crossing $C_{u u}^{e}(\mathrm{~km})$ & 123.17 & 104.09 & 121.18 & 97.1 & 87.20 & 49.2 \\
\hline First zero crossing $C_{v v}^{e}(\mathrm{~km})$ & 138.75 & 100.94 & 97.56 & 104.88 & 90.35 & 46.92 \\
\hline Second zero crossing $C_{u u}^{e}(\mathrm{~km})$ & 194.93 & 184.59 & 125.44 & 207.28 & 170.81 & 132.0 \\
\hline Second zero crossing $C_{v v}^{e}(\mathrm{~km})$ & 281.58 & 329.54 & 158.38 & 203.05 & 218.76 & 202.22 \\
\hline$U\left(\mathrm{~cm} \mathrm{~s}^{-1}\right)$ & $3.4 \pm 0.33$ & $2.25 \pm 0.23$ & $5.77 \pm 0.65$ & $3.83 \pm 0.42$ & $7.97 \pm 1.38$ & $6.68 \pm 1.74$ \\
\hline$V\left(\mathrm{~cm} \mathrm{~s}^{-1}\right)$ & $-0.6 \pm 0.4$ & $-0.51 \pm 0.24$ & $0.63 \pm 0.64$ & $0.01 \pm 0.34$ & $3.46 \pm 1.43$ & $2.4 \pm 1.53$ \\
\hline$c_{\text {zonal }}\left(\mathrm{cm} \mathrm{s}^{-1}\right)$ & $0.46 \pm 0.98$ & $0.46 \pm 0.98$ & $0.72 \pm 0.86$ & $0.72 \pm 0.86$ & $2.05 \pm 1.73$ & $2.05 \pm 1.73$ \\
\hline$c_{\text {meridional }}\left(\mathrm{cm} \mathrm{s}^{-1}\right)$ & $-0.18 \pm 0.45$ & $-0.18 \pm 0.45$ & $-0.07 \pm 0.39$ & $-0.07 \pm 0.39$ & $1.14 \pm 1.41$ & $1.14 \pm 1.41$ \\
\hline$u^{\prime} u^{\prime}\left(\mathrm{cm}^{2} \mathrm{~s}^{-2}\right)$ & $35.45 \pm 2.77$ & $19.26 \pm 1.4$ & $80.14 \pm 8.28$ & $28.75 \pm 3.16$ & $215.5 \pm 28.74$ & $122.31 \pm 27.14$ \\
\hline$v^{\prime} v^{\prime}\left(\mathrm{cm}^{2} \mathrm{~s}^{-2}\right)$ & $52.52 \pm 4.1$ & $21.94 \pm 1.6$ & $75.93 \pm 7.84$ & $26.27 \pm 2.89$ & $230.05 \pm 30.68$ & $94.57 \pm 20.99$ \\
\hline$T_{u u}^{l}($ days $)$ & $11.62 \pm 1.58$ & $10.98 \pm 1.6$ & $9.67 \pm 1.68$ & $12.72 \pm 1.39$ & $4.07 \pm 0.82$ & $5.89 \pm 0.54$ \\
\hline$T_{v v}^{l}$ (days) & $5.63 \pm 0.74$ & $7.77 \pm 0.84$ & $4.66 \pm 0.64$ & $6.29 \pm 0.75$ & $1.98 \pm 0.44$ & $3.35 \pm 0.51$ \\
\hline$T_{\text {euu }}$ (days) & $11.72 \pm 1.59$ & $13.14 \pm 1.58$ & $9.74 \pm 1.63$ & $12.95 \pm 1.25$ & $4.1 \pm 0.68$ & $9.35 \pm 2.32$ \\
\hline$T_{e v v}$ (days) & $14.43 \pm 2.42$ & $15.52 \pm 2.45$ & $7.65 \pm 1.31$ & $11.7 \pm 1.43$ & $4.14 \pm 0.69$ & $7.96 \pm 0.95$ \\
\hline$T_{\text {duu }}$ (days) & - & - & - & - & - & $22 \pm 28.7$ \\
\hline$T_{d v v}($ days $)$ & $18.92 \pm 14.94$ & $26.47 \pm 29.96$ & $19.55 \pm 50.99$ & $26.39 \pm 96.76$ & $6.95 \pm 15.12$ & $10.86 \pm 1.56$ \\
\hline$T_{\text {duu }}^{\text {theory }}$ (days) & $126.81 \pm 182.19$ & $105.17 \pm 162.85$ & $47.61 \pm 51.18$ & $557.80 \pm 3607.9$ & $17.08 \pm 14.89$ & $28.58 \pm 47.27$ \\
\hline$T_{d v v}^{\text {theory }}$ (days) & $14.78 \pm 5.32$ & $18.69 \pm 10.61$ & $7.00 \pm 1.59$ & $14.50 \pm 4.59$ & $5.62 \pm 2.14$ & $7.07 \pm 3.79$ \\
\hline$K_{x x}^{o v}\left(\mathrm{~m}^{2} \mathrm{~s}^{-1}\right)$ & $4425.3 \pm 751.11$ & $2350.2 \pm 376.99$ & $5858.7 \pm 1293.6$ & $3104.6 \pm 563.3$ & $7487.8 \pm 1876.7$ & $8563.2 \pm 3406.3$ \\
\hline$K_{y y}^{o x}\left(\mathrm{~m}^{2} \mathrm{~s}^{-1}\right)$ & $5463.2 \pm 1236.4$ & $2773.4 \pm 559.9$ & $5027.3 \pm 1099.3$ & $2818.2 \pm 560.8$ & $7617.6 \pm 1907.2$ & $7416.6 \pm 2510.1$ \\
\hline$K_{x x}\left(\mathrm{~m}^{2} \mathrm{~s}^{-1}\right)$ & $4402.4 \pm 768.4$ & $1962.4 \pm 345.1$ & $5858.6 \pm 1293.6$ & $3049.1 \pm 572.5$ & $7092.7 \pm 2118.9$ & $5433.2 \pm 1790$ \\
\hline$K_{y y}\left(\mathrm{~m}^{2} \mathrm{~s}^{-1}\right)$ & $2132.2 \pm 366.9$ & $1391.1 \pm 208.2$ & $2821.1 \pm 566.3$ & $1496.8 \pm 296.7$ & $3475.8 \pm 1072.8$ & $3087.9 \pm 1085.2$ \\
\hline
\end{tabular}

the deep Scotia Sea. This difference is due to the presence of a stronger negative lobe (Fig. 10), probably due to paired dipoles, in the strongly eddying flow of the Scotia Sea. We also present the distance at which the first and second zero crossing occur for the correlation function. This gives a sense of the distance at which the velocities broadly reverse, or the diameter of the eddies. This scale is approximately $120 \mathrm{~km}$ for the southeast Pacific Ocean and decreases in the Scotia Sea (Table 1), similar to the integral length scales. This estimate of eddy size is in broad agreement with the eddy sizes calculated for this region using SSH fields (Chelton et al. 2011). Chereskin et al. (2010) estimated wavelength of meanders to be between 250 and $300 \mathrm{~km}$, which is in good agreement with our eddy sizes (with a wavelength the size of a dipole). Broadly speaking, the spatial correlations and length scales of the residual velocity are approximately isotropic, without any clear preference for any direction.

To inspect the properties in frequency domain, we divided the trajectories into 120-day segments. Each segment was assigned its corresponding spatial bin based on its mean position and mean depth, which was then used to calculate a time series of residual velocities. The binned time series are then used to calculate the normalized Lagrangian frequency spectra $S(\omega)$, normalized by the velocity variance, of the residual velocity. The normalized Lagrangian spectra are also generally isotropic similar to the spatial correlations. We checked the rotary spectra (not shown) to look for preference of anticyclonic versus cyclonic motions and did not find any such preference.

The variance preserving form $[\omega S(\omega)]$ of the normalized Lagrangian frequency spectra (Fig. 11) generally shows a broad peak. Strikingly, the peak migrates from periods of approximately 60 days in the deep western part of the southeast Pacific Ocean to periods of 20 days in the shallow Scotia Sea. Also, the peak in the deeper bin is located at relatively lower frequencies than the shallower bin. This shift of peak in frequency can be explained simply as a consequence of Doppler shifting in the presence of mean flow. In this region of the ACC, the eddies persist for times on the order of few weeks to months and have propagation speeds less than $1 \mathrm{~cm} \mathrm{~s}^{-1}$ (Chelton et al. 2011). This (fixed flow regime) implies that as the floats move through the eddies (at 5$10 \mathrm{~cm} \mathrm{~s}^{-1}$ ) they experience a nearly stationary eddy field and that the time variability in the time series of the floats is generated mostly by the floats meandering through the stationary eddies. In this setting, a slowermoving float, as in the southeast Pacific Ocean, will experience the variability at lower frequencies, while a 

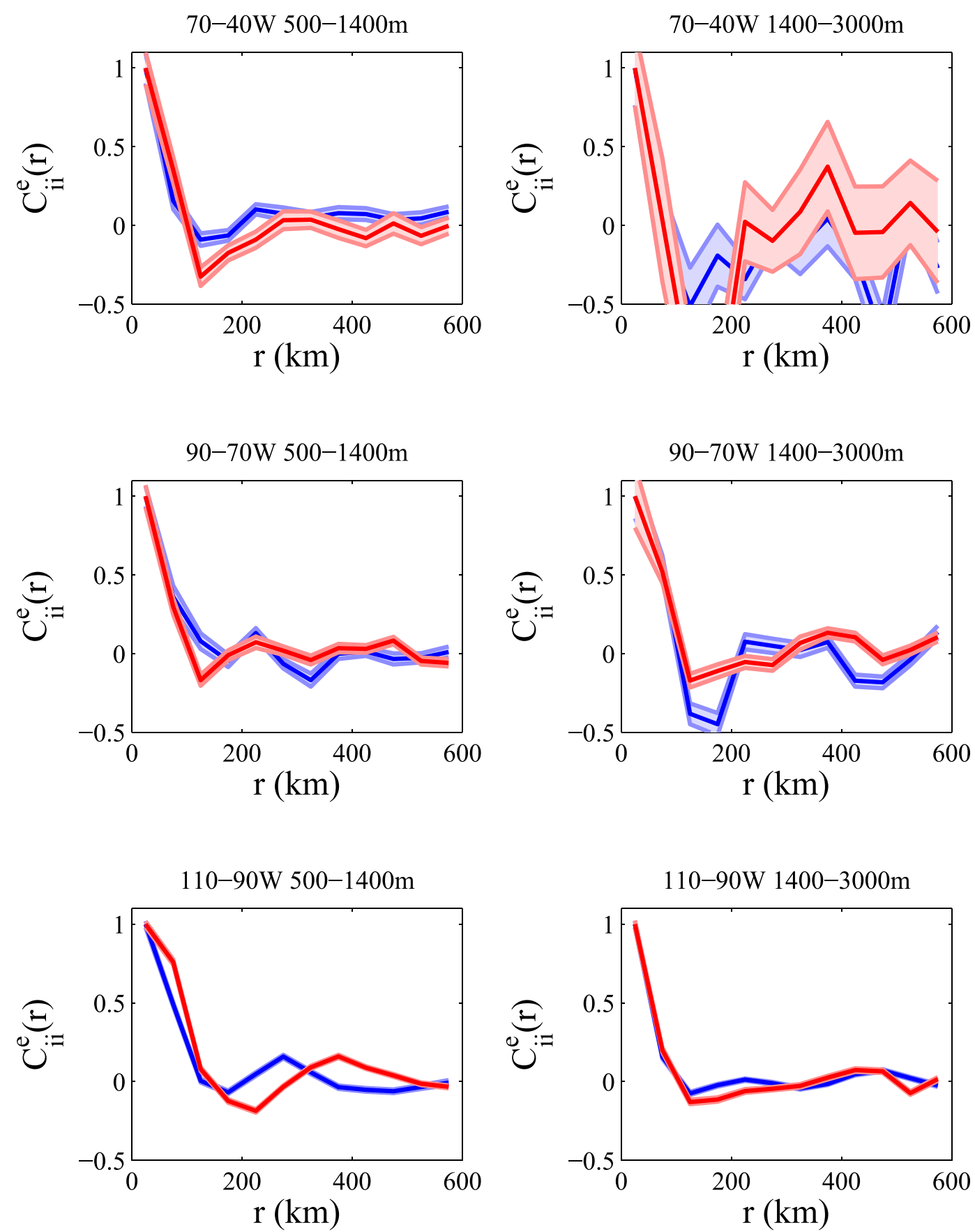

FIG. 10. Quasi-Eulerian spatial correlation functions calculated from floats. Zonal $\left(C_{u u}^{e}\right)$ is blue and meridional $\left(C_{v v}^{e}\right)$ is red. Error bars are standard errors in each distance bin.

faster-moving float, as in the Scotia Sea, will experience the variability at higher frequencies. Chen et al. (2015) formally showed that the Lagrangian and Eulerian frequency spectra can be related as $S_{\text {Eulerian }}(k, l, \omega)=$ $S_{\text {Lagrangian }}(k, l, \omega+|U| k)$, where $|U|$ is the zonal mean flow, $k$ is the zonal wavenumber, and $l$ is the meridional wavenumber.
Our dataset, similar to previous float studies (Rupolo et al. 1996), shows a commonly observed spectral shape (Fig. 12). The spectra plateau at lower frequencies is required for the Lagrangian time scale and diffusivity to be well defined as $S(0)=2(2 \pi) T_{l}$, where $T_{l}$ is the Lagrangian integral time scale, $S(0)$ is the normalized Lagrangian frequency spectrum at zero frequency that was 

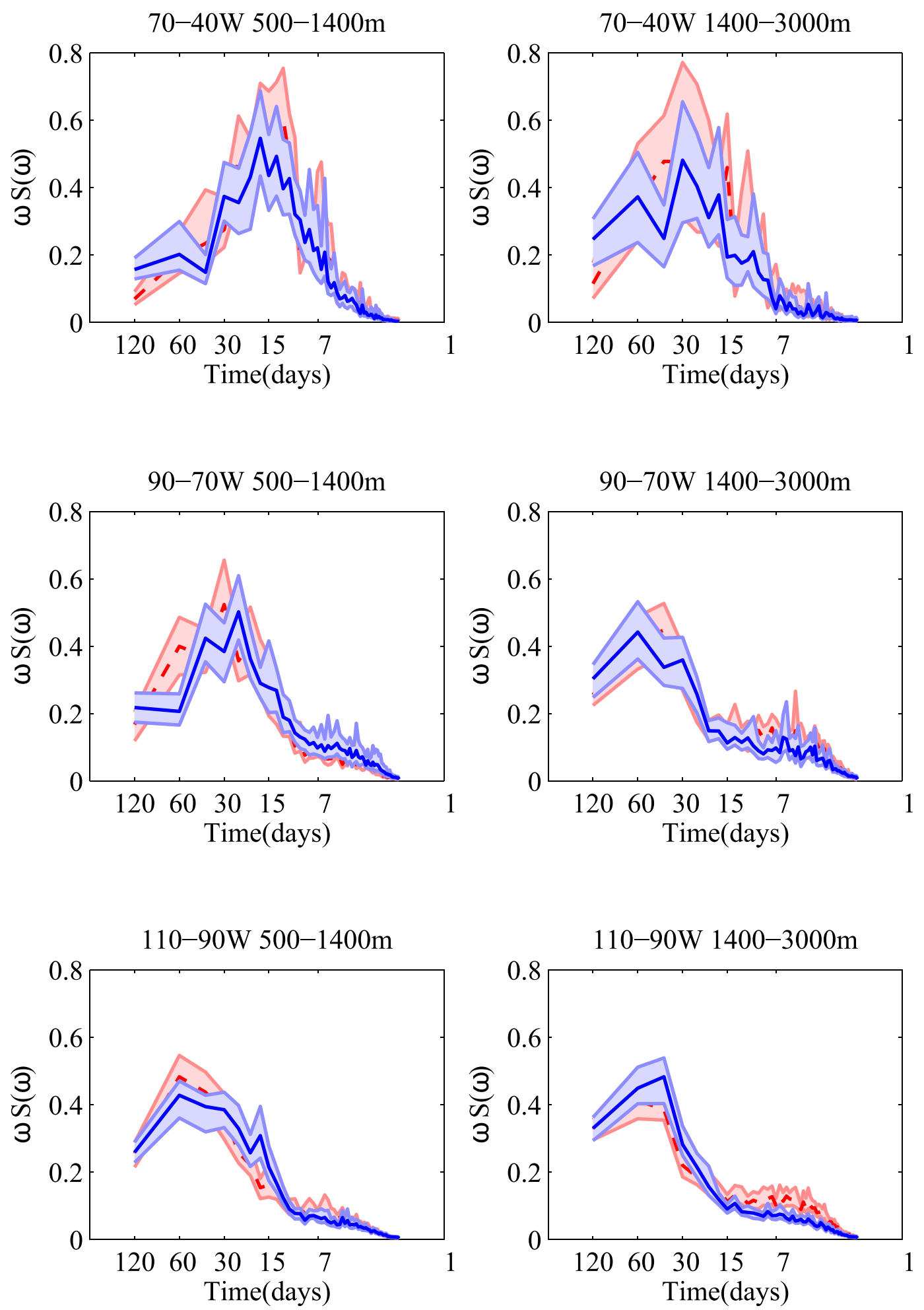

FIG. 11. Variance preserving normalized Lagrangian spectra from float velocity. Zonal velocity is blue and meridional velocity is red. Error bars are obtained by bootstrapping and shown as lighter color shading. 

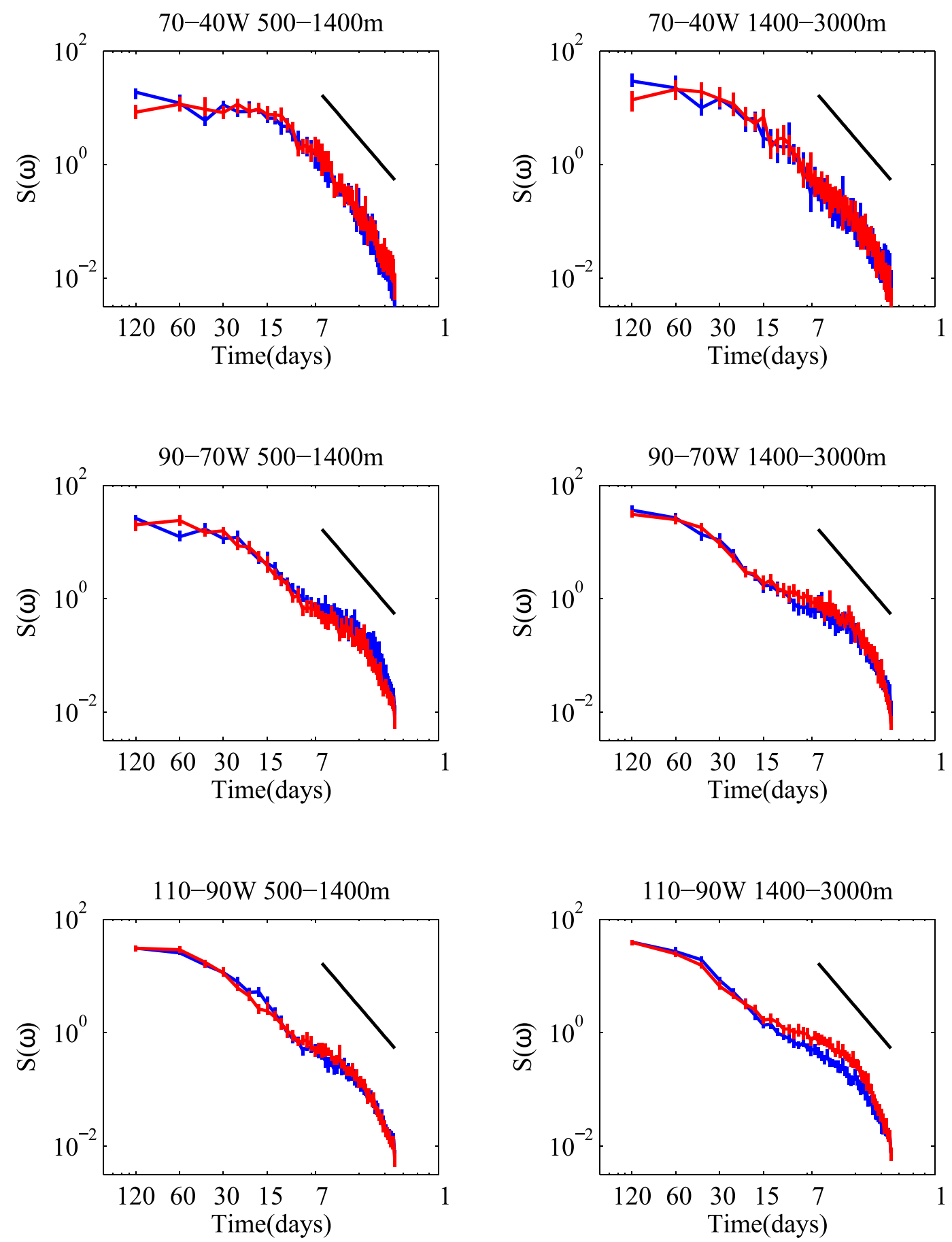

FIG. 12. Lagrangian spectra on a log-log plot. Zonal velocity is blue and meridional velocity is red. The black line represents a slope of -3 . Error bars are obtained by bootstrapping and are shown as small lines extending over the limits of the errors.

normalized by the velocity variance, and the $2 \pi$ appears because of the way the spectra were defined. The spectra at the highest frequencies (periods smaller than 7 days) have a spectral slope that is steeper than -3 , which is required for the Lagrangian microscale or the acceleration time scale to be well defined (Hua et al. 1998; Rupolo et al. 1996). There is also a range in between with spectral slopes of approximately -2 , as would be expected from a simple first-order stochastic model of the variability (LaCasce 2008). 
The binned time series, 120-day segments defined above were also used to calculate the velocity autocorrelation:

$$
R_{i i}^{l}(\tau)=\frac{\left\langle u_{i}^{\prime}(t) u_{i}^{\prime}(t+\tau)\right\rangle}{\left[\left\langle u_{i}^{\prime}(t) u_{i}^{\prime}(t)\right\rangle\right]} .
$$

The angular brackets represent averaging over the trajectories that are present in the bin. This correlation is then used to find the Lagrangian integral time scale:

$$
T_{i i}^{l}=\int_{0}^{\infty} R_{i i}^{l}(\tau) d \tau
$$

Structurally, $R_{i i}^{l}$ looks similar to $C_{i i}^{e}$ : there is a decay and oscillations, usually with a prominent negative lobe. This structure would be expected based on a turbulent field in which the flow decorrelates in time but also has the presence of significant looping and meandering. This can be approximated as a function of the form

$$
R_{i i}^{l}(t)=e^{-t / T_{e i i}} \cos \left(2 \pi t / 4 T_{d i i}\right),
$$

where $T_{e i i}$ is a decay scale, $T_{d i i}$ is the time of first zero crossing or the meander time scale and the subscripts $i$, and $j$ represents the directionality. This form is fit to the mean autocorrelation functions; the parameters and error in fits are calculated using bootstrapping. This is done using the Monte Carlo-like method of producing noisy correlation functions as described above, used for spatial correlation integration. Previous observational studies using Lagrangian measurements (Sallée et al. 2008b; Garraffo et al. 2001) have fit a functional form of the type shown above or similar forms. It should be remembered that this fitting exercise primarily captures the decay and the first negative lobe of the autocorrelation function, which produces a "local" estimate of the time scale. The analytical integral of this chosen autocorrelation function gives an effective Lagrangian integral time scale:

$$
T_{i i}^{l}=\frac{4 T_{e i i} T_{d i i}^{2}}{\pi^{2} T_{e i i}^{2}+4 T_{d i i}^{2}} .
$$

Klocker et al. (2012) applied the mixing suppression theory (Ferrari and Nikurashin 2010) to particles instead of tracers and derived an autocorrelation function of the same form as (7). This links physical processes to the presence of the two scales using dynamical arguments. Their theory was derived for a randomly forced Rossby wave solution to a quasigeostrophic system. The nonlinear terms, used as forcing for the Rossby waves, were parameterized as a sum of a white noise process and linear damping. The decay time scale $\left(T_{e i i}\right)$ was associated with the linear damping time scale. The oscillation time scale $\left(T_{d i i}\right)$ was based on the dominant wavenumber multiplied by the difference of mean speed and observed phase speed. This difference is associated with the mean PV gradient based on the dispersion relation for linear Rossby waves. Their expression for the autocorrelation is [their (18)]

$$
R_{v v}\left(t^{\prime}\right)=\frac{2 k^{2} \mathrm{EKE}}{K^{2}} e^{-\gamma t^{\prime}} \cos \left[k\left(c_{w}-U\right) t^{\prime}\right],
$$

where $k$ is the zonal wavenumber, $K$ is the amplitude of the total wavenumber, $\gamma$ is the linear damping constant, $c_{w}$ is the observed phase speed, and $U$ is the mean zonal speed. Based on this model, a stronger PV gradient (larger $\left|c_{w}-U\right|$ ), holding the damping time scale constant, would call for the oscillation time scale to be relatively smaller. This would, in turn, imply a more prominent negative lobe in the autocorrelation function. A larger negative lobe implies a smaller Lagrangian integral time scale and smaller eddy diffusivities.

Based on (9) and using the same form as (7), we can calculate a theoretical meander time scale using the binned mean flow, observed feature propagation speeds $\left(c_{w i}\right)$ from $\mathrm{Fu}(2009)$, and observed length scales:

$$
2 T_{d i i}^{\text {theory }}=\pi /\left[k_{j}\left(c_{w j}-U_{j}\right)\right],
$$

where the repeated index does not imply summation (as we are not following the Einstein notation in this section).

These time scales are presented in Table 1 . The integral time scale $\left(T_{i i}^{l}\right)$ approaches the decay time scale $\left(T_{e i i}\right)$ as the meander time scale $\left(T_{d i i}\right)$ gets relatively longer. This happens when the meander time scale is long since the amplitude of the autocorrelation function will decay to a very small value before the negative lobe can significantly affect the integral. This leads to the fitted zonal meander time scale $\left(T_{d u u}^{\text {theory }}\right)$ being very large ( $>500$ days) for most of the bins, and those results are not shown in the Table.

The decay time scale is about 10 days in the southeast Pacific Ocean and 6 days in the Scotia Sea, and generally increases with depth. This is to be expected if simple scaling arguments like $T_{\text {eii }}^{2}\left[1 /|k|^{2} u_{i i}^{\prime 2}\right]$ roughly hold and the length scales do not vary much with depth. This result is different than the result in Lumpkin et al. (2002); they found that the time scale remained roughly constant with depth as the length scale and EKE decayed with depth in the North Atlantic Ocean. The Eulerian time scale calculated using current meters in different parts of the ACC are close to 20 days (Phillips and Rintoul 2000). It is not surprising that the Eulerian time 
scales are larger than the Lagrangian time scale, as in the ACC the floats propagate through Eulerian features faster than the Eulerian features pass through a region (Middleton 1985).

We then use these time scales and EKE to calculate the eddy diffusivities $\left(\kappa_{i i}=\mathrm{EKE} \times T_{i i}^{l}\right.$; Taylor 1921). These diffusivity estimates are also local diffusivity estimates, similar to the time scales, because of the nature of the fitting procedure to an early time autocorrelation function. The meridional diffusivities are similar in the two southeast Pacific Ocean bins $\left(110^{\circ}-90^{\circ} \mathrm{W}\right.$ and $90^{\circ}$ $\left.70^{\circ} \mathrm{W}\right)$ : approximately $2500 \pm 500 \mathrm{~m}^{2} \mathrm{~s}^{-1}$ in the shallower bins and $1400 \pm 250 \mathrm{~m}^{2} \mathrm{~s}^{-1}$ in the deeper bins. The meridional diffusivity is approximately $3200 \pm 1000 \mathrm{~m}^{2} \mathrm{~s}^{-1}$ in the Scotia Sea. The zonal diffusivities are generally greater, and this is to be expected because they are enhanced by both the mean horizontal shear and mean vertical shear, which cannot be completely removed by removing a bin-averaged mean to find the residual velocities. In the Scotia Sea both the zonal and meridional diffusivities seem to be affected by these shears.

Using the result from the above analysis, that the time scales and the diffusivities are similar across the southeast Pacific Ocean, we use all the tracks between $110^{\circ}$ and $70^{\circ} \mathrm{W}$ and increase the number of vertical bins to better resolve the vertical structure of diffusivity. The time scales and diffusivity are calculated the same way as above by fitting (7) to the autocorrelation function and calculating the time scales. The fitting procedure provides the decay time scale $\left(T_{e i i}\right)$ and the meander or zero crossing time scale $\left(T_{d i i}\right)$. The Lagrangian time scale is then calculated using (8). The decay time scale shows a peak at $1100 \mathrm{~m}$, the meander time scale shows a peak at $1500 \mathrm{~m}$ corresponding to the critical level, and the Lagrangian integral time scale shows a peak at $1500 \mathrm{~m}$ (Fig. 13b).

The diffusivity calculated using only the decay time scale $\left(K_{i i}^{o}=\mathrm{EKE} \times T_{e i i}\right)$, the diffusivity calculated using the Lagrangian integral time scale (called the suppressed or expected diffusivity, $K_{i i}=\mathrm{EKE} \times T_{i i}^{l}$ ), and the theoretical estimate of diffusivity $\left\{K_{i i}^{\text {theory }}=\left[4 \mathrm{EKE} \times T_{\text {eii }} \times\right.\right.$ $\left.\left.\left(T_{d i i}^{\text {theory }}\right)^{2}\right] /\left[\pi^{2} T_{e i i}^{2}+4\left(T_{d i i}^{\text {theory }}\right)^{2}\right]\right\}$ from Klocker et al. (2012) are shown together (Fig. 13a). The eddy diffusivity $(K)$ decreases from around $2800 \pm 600 \mathrm{~m}^{2} \mathrm{~s}^{-1}$ at $700 \mathrm{~m}$ to around $990 \pm 200 \mathrm{~m}^{2} \mathrm{~s}^{-1}$ at $1900 \mathrm{~m}$. In the calculation of $K^{\text {theory }}$, the observed decay time scale is used along with a length scale of $100 \mathrm{~km}$, approximately the eddy size, as this length scale provided a better fit against the observed diffusivity than using the calculated integral length scale from spatial autocorrelations. Thus, the theoretical value should be regarded as a fitted form rather than an absolute prediction. The presence of mean flow or the presence of a negative lobe in the autocorrelation function suppresses diffusivity, which is evident as $K_{i i}^{o}$ is greater than $K$ and the Lagrangian integral time scale is smaller than the decay time scale everywhere. Even though the Lagrangian integral time scale shows evidence of a middepth $(\sim 1500 \mathrm{~m})$ maximum, no such maximum is seen in the diffusivities. This suggests that the structure of the diffusivities in the ACC is more strongly controlled by the EKE, rather than the Lagrangian time scale. This is to be expected as the EKE varies by a factor of 3-4 in the vertical (Fig. 7), whereas the Lagrangian integral time scale variations are less than $20 \%$.

Geographically binned eddy diffusivities (Davis 1991), as for horizontal velocities in previous sections, were not calculated for two main reasons. First, it has been pointed out that diffusivities calculated as $\left\langle X^{2}\right\rangle / 2 T$ or some similar measure (LaCasce 2008) can take 6 months or longer to asymptote to a constant value. Hence, calculating binned diffusivities is problematic, as the floats spend only a fraction of 6 months in a given bin. Second, the floats are spread in the vertical; for the mean flow calculations we could use the EB assumption to rescale the float velocities to a common depth level, but no similar procedure can be applied to rescale the float trajectory to a common depth level. What we have presented in this section are average diffusivities, but with the choice of the averaging over a very large area ( $30^{\circ}$ latitude $\times 10^{\circ}$ longitude), much larger than the bins for the mean flow. Previous float and drifter studies have presented diffusivities in geographic bins of the same size as those used for mapping the mean flow (e.g., Ollitrault and Colin de Verdière 2002; Swenson and Niiler 1996), but using data that were primarily limited to a certain depth level or the sea surface; even so, attributing error estimates to geographic bins may be problematic in regions of strong flow.

Thus far, only zonal and meridional diffusivities have been estimated. As the aim of the DIMES experiment was to quantify cross-stream diffusivities, we continue the analysis in cross-SSH coordinates with dispersion calculated for the southeast Pacific Ocean and the Scotia Sea float tracks divided into two depth bins (Fig. 14). The diffusivity is estimated as $\left\langle X^{2}\right\rangle / 2 T$, where $X$ is the cross-stream distance. This calculation differs from the ones presented in LaCasce et al. (2014) in three ways. First, their study did not separate the data into depth bins to tease out a vertical structure of eddy diffusivity, which is our main goal here. Second, we produce error estimates using boot strapping, which was not done previously. Finally, we also attempt to produce estimates for the Scotia Sea.

The diffusivity estimates, using the relation above $\left(\left\langle X^{2}\right\rangle / 2 T\right)$, are approximately $690 \pm 150$ and $1000 \pm$ $200 \mathrm{~m}^{2} \mathrm{~s}^{-1}$ for the shallow $(500-1400 \mathrm{~m})$ and deep 

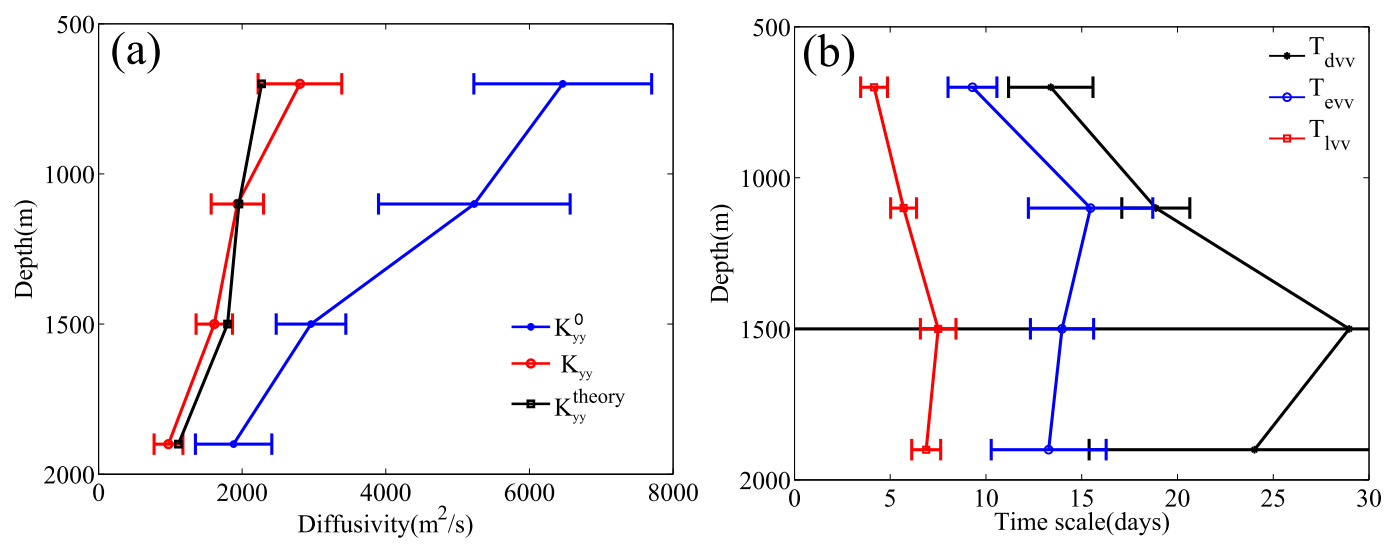

FIG. 13. (a) Vertical structure of meridional diffusivity in the southeast Pacific Ocean. The diffusivity scale $K_{y y}^{o}=\mathrm{EKE} \times T_{e v v}$ (blue) is calculated using only the decay time scale from the floats, the estimated value $K_{y y}=\mathrm{EKE} \times T_{v v}^{l}$ (red) is calculated using the full Lagrangian time scale from the floats, and the value $K_{y y}^{\text {theory }}=\left[4 \mathrm{EKE} \times T_{e i i} \times\left(T_{d i i}^{\text {theory }}\right)^{2}\right] /\left[\pi^{2} T_{e i i}^{2}+4\left(T_{d i i}^{\text {theory }}\right)^{2}\right]$ (black) is calculated using the decay time scale from the floats and meander time scale from theory, which assumed a length scale of $100 \mathrm{~km}$. (b) Vertical structure of time scales in the southeast Pacific Ocean, calculated by the fitting the velocity autocorrelation to (7); $T_{d v v}$ is the first zero crossing and $T_{e v v}$ is the decay scale in the meridional direction. Variable $T_{l v v}$ is the Lagrangian time scale using (8) in the meridional direction. Variable $T_{d v v}$ has very large error bars at $1500 \mathrm{~m}$ because the autocorrelation decays quickly without a prominent negative lobe.

(1400-2500 m) southeast Pacific Ocean floats. Note that the deeper-level estimates of diffusivity in the southeast Pacific Ocean are similar to the meridional diffusivities calculated above using the autocorrelation fitting procedure. In the Scotia Sea, the diffusivities are approximately $1200 \pm 500 \mathrm{~m}^{2} \mathrm{~s}^{-1}$ for both shallow $(500-1000 \mathrm{~m})$ and deep floats (1000-2000 m), but with larger error bars. These depth ranges are different in the two basins and were chosen to allow for an almost equal data distribution in both depth bins. The division between the southeast Pacific Ocean and the Scotia Sea was chosen to be $70^{\circ} \mathrm{W}$. The error bars on the dispersion are calculated as one standard deviation of all bootstrapping samples where the trajectories are resampled, allowing for repeats, and the dispersion curves calculated 1000 times. For the diffusivity curve, the error is the range of slopes that fit between the error bars of the dispersion curves. In the southeast Pacific Ocean there are about 55 floats for each depth bin on the first day, and this number only marginally decreases to about 45 by day 250 . However, in the Scotia Sea on the first day, there are about 40 floats, but within 150 days this number decreases to around 15 .

The estimate of diffusivity at the shallower level in the southeast Pacific Ocean is significantly smaller than estimates provided earlier by the fitting procedure, almost by a factor of 4 . This is because the diffusivities and Lagrangian time scale estimates do not asymptote to a fixed value for very long times, whereas the fitting procedure only produces early time results. A similar longterm decay, beyond the first negative lobe, was also noted in Griesel et al. (2015). LaCasce et al. (2014) had also shown that the diffusivities estimates take a long time to settle, and after 6 months the shallower-level diffusivities are smaller than the deeper-level diffusivities. This can be understood by looking at the dispersion (Fig. 14a); the dispersion for the shallow floats in the southeast Pacific Ocean does not grow linearly but instead saturates after some initial ( $\sim 70$ days) increase, whereas the dispersion from the deeper floats in the southeast Pacific Ocean increases almost linearly, as would be expected for a diffusive process. This almost linear increase for the deeper floats is the reason that the estimates using the autocorrelation fitting and dispersion produce similar results. To confirm this, the model particle calculations of LaCasce et al. (2014) were revisited (not shown). Calculations of dispersion at shallower levels showed saturation after an initial growth period of about 50-100 days, similar to the saturation seen in Fig. 14.

Saturation of dispersion at long times, as seen at the shallower level, can be expected if the diffusivity is inhomogeneous in the cross-stream direction, with regions of high diffusivity being flanked by regions of low diffusivities. Considering the mean flow field calculated in the previous section, we infer that these inhomogeneities are a result of time mean jets acting as barriers to mixing at shallower levels. The long-term effects of barriers on mixing would not be captured by the fitting of autocorrelation by (7) as done previously in this section, nor would this behavior be predicted by the form of 

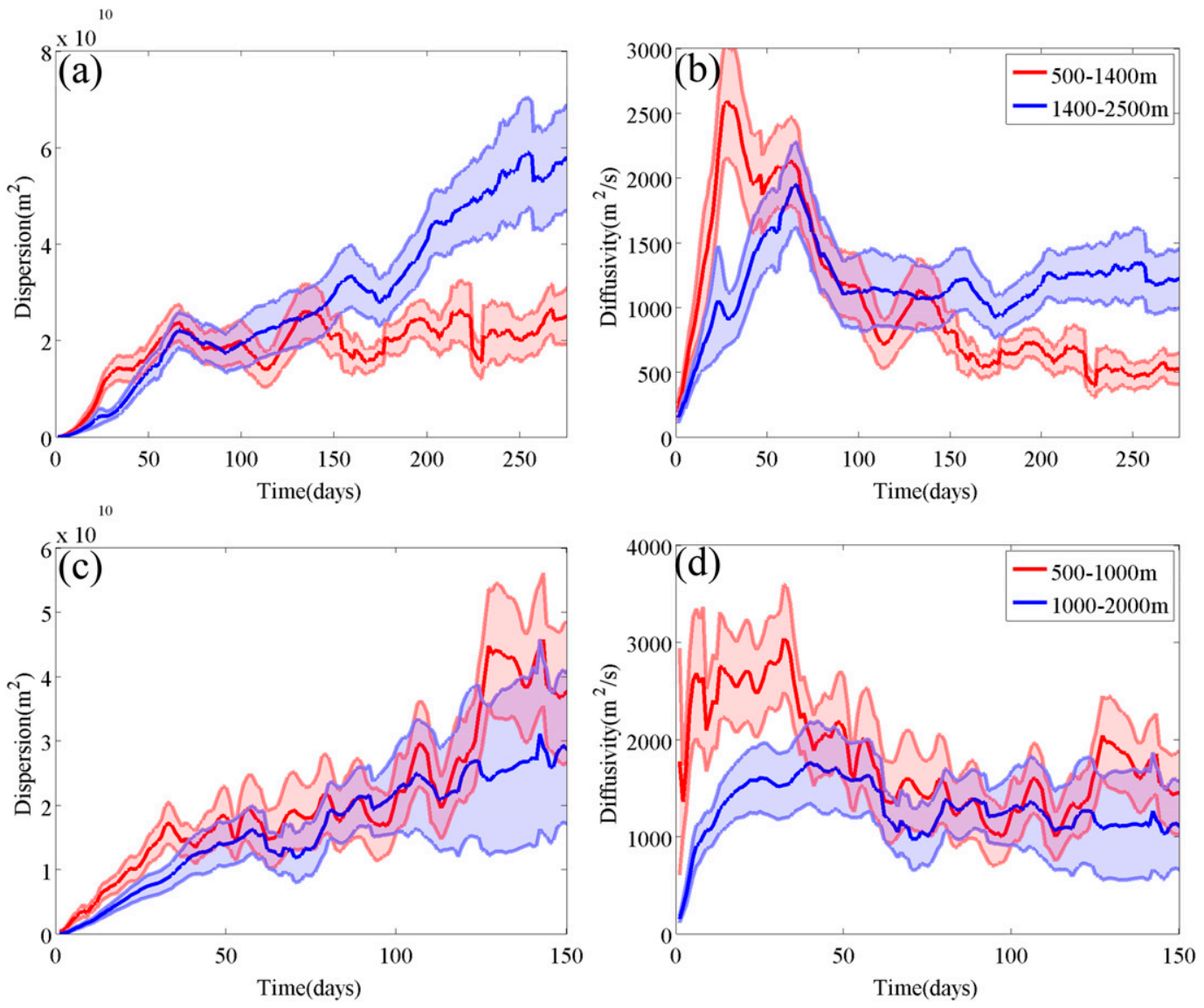

FIG. 14. (a) Dispersion and (b) diffusivity for the floats launched west of $100^{\circ} \mathrm{W}$ in the southeast Pacific Ocean divided into vertical bins encompassing 500-1400 m and 1400-2500 m. (c) Dispersion and (d) diffusivity for the floats that crossed $70^{\circ} \mathrm{W}$ into the Scotia Sea and divided into vertical bins encompassing 500-1000 $\mathrm{m}$ and 1000 $2500 \mathrm{~m}$.

diffusivity derived by Klocker et al. (2012) or Ferrari and Nikurashin (2010). We also note that the discrepancy between cross-stream and meridional diffusivities is not due to the choice of coordinates, as in the southeast Pacific Ocean the SSH contours are almost zonal (Tulloch et al. 2014).

In the Scotia Sea the use of the across-SSH dispersion allows the quantification of cross-streamline diffusivity, which cannot be done by calculating zonal and meridional diffusivities (Table 1). It can be asked if the spreading in the Scotia Sea is indeed Gaussian and diffusive or, on the contrary, anomalous; hence, a nondiffusive parameterization is needed to represent it. With our limited dataset, we are not able to answer this question conclusively.

Overall, our results, properly interpreted, appear to be consistent with previous notions and results, discussed in detail in the next section. Jets are faster at shallower levels and act as stronger barriers to mixing, while at deeper levels the jets slow down and the barrier effect becomes weaker. Also, the regions between the jets at shallow levels are more strongly mixed than at deeper levels simply because of the higher EKE at shallower levels.

\section{Discussion}

The DIMES floats provide a striking set of trajectories that quite clearly show both the large-scale circulation and the macroturbulent nature of the flow in the ACC. The floats sampled depths between 500 and $2500 \mathrm{~m}$ from $105^{\circ}$ to $40^{\circ} \mathrm{W}$, primarily between the SAF and PF. At a depth level of approximately $1400 \mathrm{~m}$ in the southeast Pacific Ocean, the mean speeds ranged from $6 \mathrm{~cm} \mathrm{~s}^{-1}$ in the jets to $1 \mathrm{~cm} \mathrm{~s}^{-1}$ between the jets, whereas in the Scotia Sea the typical speeds were almost doubled. The EKE in the two regions also differed substantially, 10$60 \mathrm{~cm}^{2} \mathrm{~s}^{-2}$ in the southeast Pacific Ocean and 20$140 \mathrm{~cm}^{2} \mathrm{~s}^{-2}$ in the Scotia Sea, at similar depths. The EKE and the mean speeds increase dramatically as the flow 
crosses over the Hero and Shackleton fracture zones, from the relatively calm southeast Pacific Ocean to the vigorously unstable Scotia Sea. Our results (below $500 \mathrm{~m}$ depth) show congruence with the SSH-derived velocities but little change with depth, we do not see any evidence of greater turning in deeper versus shallower bins. This good semblance to the flow at the surface is observed by satellites and leads us to believe that the flow is EB to the first order. Our results show excellent qualitative comparisons and good quantitative comparisons to previous studies in limited regions, discussed as the end of section 3, and extend our current maps of the middepth flow over a larger region of the southeast Pacific Ocean and Scotia Sea.

The integral length scales generally varied between 20 and $60 \mathrm{~km}$ and the length scale of the first zero crossing, which we believe is the dominant eddy length scale, varied between 50 and $120 \mathrm{~km}$, generally decreasing from the southeast Pacific to the Scotia Sea and with depth. This decrease with depth bears some resemblance to the quasigeostrophic simulations of Smith and Vallis (2001) with the case of nonuniform stratification. The mean jets, seen in the maps of the mean fields, meander at length scales similar to the eddy length scales in the southeast Pacific Ocean and scales set by the scale of the topography in the Scotia Sea. These meandering structures of the southeast Pacific Ocean are probably transient, as there is no topography that can maintain them, but persist over time scales that are longer than time scale of passage for the particles through the region, which is the reason they appear in the mean field, and could be significantly affecting the spreading of tracers.

The spacing between the jets in the southeast Pacific Ocean basin, which does not have extreme topographic features like the Scotia Sea, is initially set upstream by the spacing between the fracture zones in the PacificAntarctic Ridge (upstream of the experiment site). Subsequently, the approximately $200-\mathrm{km}$ spacing seen in this region is probably set by a combination of the weak nonuniformities in barotropic PV $(f / H)$ gradients, upstream effect of the seamounts, and turbulent mechanisms operating on the Rhines scale (approximately $200 \mathrm{~km}$ ). The topographic features will play a role in setting the circulation at middepth if the velocities along the bottom are nontrivial, which (for depths greater than $2500 \mathrm{~m}$ ) is a criteria that cannot be tested by these data. However, previous studies have shown the presence of strong bottom flows in a few locations in the ACC. The visual correspondence between the $f / H$ field and mean flow features seen here leads us to believe that even in this relatively smooth and deep region of the ACC, the bottom exerts some influence on the flow.
Quantifying the isopycnal stirring was one of the main motivations behind the DIMES float experiment. The floats provide the first ground truth of the stirring processes at work in the ACC. They clearly show the presence of jets in the flow and strongly suggest that these jets form transport barriers, whose effect decreases with depth. Although the long-time limit of diffusivity in the southeast Pacific Ocean shows stronger mixing at depth, with cross-stream diffusivities of $690 \pm 150 \mathrm{~m}^{2} \mathrm{~s}^{-1}$ between 500 and $1400 \mathrm{~m}$ and $1000 \pm 200 \mathrm{~m}^{2} \mathrm{~s}^{-1}$ between 1400 and $2500 \mathrm{~m}$, a more local estimate of diffusivity, produced by fitting a functional form to the autocorrelation function, shows a decrease with depth that follows the general structure of the EKE, as the variation of the Lagrangian time scale with depth is small. The Lagrangian time scales, which do show a middepth maximum near the critical level, seem to be suppressed in accordance with the mixing length suppression arguments of Ferrari and Nikurashin (2010).

The vertical structure of the integral time scale and relation to mixing has previously been discussed by Lumpkin et al. (2002), who observed that deep Lagrangian time scales from float measurements in the North Atlantic Ocean show only modest increases with depth, whereas eddy energy decreases with depth much more rapidly. This was shown to be consistent with a field of rapidly evolving nonlinear eddies and relatively slow wave speeds. Similarly, but from an analysis of numerical simulations of the ACC, Griesel et al. (2015) concluded that the vertical structure of mixing is dominated by that of the EKE.

In the last few years a number of studies have addressed the eddy diffusivity and its vertical structure in the ACC. Using the data from the DIMES experiment, LaCasce et al. (2014) presented a single vertically averaged isopycnal diffusivity from a subset of the float data, as done here, and Tulloch et al. (2014) provided a measure of diffusivity at the deeper isopycnal level based on tracer measurements. These studies also presented a vertical structure of diffusivity that was calculated by releasing particles and tracers in a model and advecting them using the model velocity field. Their modeling results showed that the vertical structure of diffusivity had a middepth maximum of about $1000 \mathrm{~m}^{2} \mathrm{~s}^{-1}$ at approximately $2000 \mathrm{~m}$, and it was reasoned that this was a result of mixing length suppression at shallower depths in the presence of a stronger, large-scale mean flow. However, it took longer than 6 months to asymptote to this value using the particles, and a long-term (100-500 days) linear fitting was done to the second moment of the tracer concentrations.

In contrast, Bates et al. (2014) presented an areaaveraged diffusivity by fitting a form of the result from 
Ferrari and Nikurashin (2010) to SSH observations and ECCO output and did not obtain a middepth maximum in diffusivity. Bates et al.'s (2014) results were based on using a length scale that was calculated from SSH fields (Chelton et al. 2011), assuming it to be the dominant length scale. We showed that this choice of length seems to be crudely correct for estimation of local diffusivities. Recently, Chen et al. (2015) provided diffusivities in the DIMES region using an approach that accounts for contributions of multiple length scales by integrating over the wavenumber-frequency spectra in the region. Interestingly, their spatial maps of eddy diffusivities show a significant degree of inhomogeneity. To calculate a single vertical profile of eddy diffusivity over the region, they do a simple area averaging, similar to Bates et al. (2014). They obtain some hints of a middepth maximum in their results, but generally the trend of eddy diffusivity is to decrease with depth. Griesel et al. (2015) also used a numerical model and particle trajectories, which were 130 days long, and did not observe a middepth maximum of diffusivity in the southeast Pacific Ocean. Naveira Garabato et al. (2011) calculated mixing lengths in the ACC using hydrographic data and showed the presence of suppressed mixing lengths in frontal regions of the ACC, at least in regions of smooth topography and essentially zonal jets. Naveira Garabato et al. (2011) applied the mixing suppression ideas in a more local sense, by calculating the mixing length as the RMS temperature fluctuation divided by the large-scale temperature gradient on neutral surfaces.

In summary, the recent results described above can be divided into three categories: localized synoptic estimates (Naveira Garabato et al. 2011), spatially averaged Eulerian estimates (Bates et al. 2014; Chen et al. 2015; Griesel et al. 2015), and long-term (6 months or longer) estimates from Lagrangian passive tracers (LaCasce et al. 2014; Tulloch et al. 2014). The discrepancy between the spatially averaged Eulerian estimates, which are similar and compare well to our estimates using a functional fit to the Lagrangian autocorrelation function (Fig. 13a), and long-term Lagrangian passive tracer estimates, which are similar and compare well to our second estimate using long term cross-stream dispersion calculations (Fig. 14), arises because of the nature of the averaging used to estimate a mean diffusivity over a large region. The correct way to average diffusivities in a crossstream direction was shown in Nakamura (2008) for the atmospheric case. Using a 1D, zonally averaged model, the correct predictor of eddy diffusivities was shown to be the harmonic average $\left\{K_{\text {average }}=\left[\int 1 / K(y) d y\right]^{-1}\right\}$, where regions of low mixing dominate the average. This model holds if the region has barriers that are invariant in time; a zonally uniform flow (along stream) might be a good assumption for the southeast Pacific Ocean, as discussed earlier. Hence, a Lagrangian passive tracer spreads through a region and converges to the harmonic mean rather than an area average, as was made in the Eulerian estimates.

The regions within the ACC where the EKE is high and the mean flow is weaker, such as between localized jets, have large diffusivities and are well-mixed regions, while the regions of strong jets act as barriers to crossstream mixing. However, if the jets merge and split, they might not always be barriers to mixing. Probably because the southeast Pacific Ocean is a relatively simple region, the jets persist for long durations without much splitting and merging and act as barriers. This nature of the southeast Pacific Ocean was previously noticed by Thompson et al. (2010), who showed in a numerical model that the region between the Udintsev fracture zone and the Drake Passage had the greatest number of distinct PV pools or regions of homogenized PV, compared to any other region of the Southern Ocean, suggesting that strongly mixed regions exist in the southeast Pacific Ocean but that there is little mixing between them.

The potentially important role of the Scotia Sea to cross-stream mixing makes estimates for this region of great interest. There are fewer data in the Scotia Sea, however, and this lack of data produces noisier estimates, with average cross-stream diffusivity of approximately $1200 \pm 500 \mathrm{~m}^{2} \mathrm{~s}^{-1}$ both in the shallow and deep bins. The results for the Scotia Sea are plagued not only by the scarcity of data but also by the presence of an extremely complex mean flow pattern. The complexity of topography in this region can create flow structure in the deeper layers significantly different from that in the flow above, leading to strong vertical motion and currents that (locally) cross the core of the ACC. One example of this is the generation of middepth vortices from the flow along the northern boundary of the Scotia Sea that move southward, across the major fronts (Brearley et al. 2014). Another example is seen in the floats that continued east in the Scotia Sea, instead of crossing over the North Scotia Ridge into the Argentine basin (Fig. 11). These deep, topographically linked currents can transport water across the major fronts of the ACC in a nondiffusive fashion and indeed may be a crucial component of overturning.

The ACC is not zonally homogeneous, and in most regions the jets are transient features of flow that do indeed merge and split. In such a complex system, it is not clear that a simple measure of mixing is appropriate. Several approaches to estimating the diffusivity lead to the conclusion that strong inhomogeneities exist in this quantity, related to jets and thin barriers to mixing within the broader ACC system. This may have led to 
disparate previous results, based on the chosen averaging method. Using Lagrangian observational methods, however, we are able to reveal some of this complexity and point to dynamical structure in the flow that controls mixing.

Acknowledgments. We thank the captains and crews of US1 2009 R/V Roger Revelle, US2 2010 R/V Thomas G. Thompson, UK1 2009 RRS James Cook, UK2 2010 RRS James Cook, UK3 RRS James Cook, and UK4 2012 RRS James Clark Ross, all of which contributed to the success of the isopycnal (float) component of DIMES, for their willing help and support. The marine operations groups of SIO, UW, BAS, and NERC were of the utmost importance for their professional work and willing support at sea in good and in difficult weather. We would also like to thank Dr. Catherine Hancock at GFDI for helping immensely with the processing of RAFOS float data. D.B. and K.S. would like to acknowledge support from NSF OCE 1231803, NSF OCE 0622670, and NSF OCE 0822075.

\section{REFERENCES}

Barré, N., C. Provost, A. Renault, and N. Sennéchael, 2011: Fronts, meanders and eddies in Drake Passage during the ANTXXIII/3 cruise in January-February 2006: A satellite perspective. Deep-Sea Res. II, 58, 2533-2554, doi:10.1016/ j.dsr2.2011.01.003.

Bates, M., R. Tulloch, J. Marshall, and R. Ferrari, 2014: Rationalizing the spatial distribution of mesoscale eddy diffusivity in terms of mixing length theory. J. Phys. Oceanogr., 44, 15231540, doi:10.1175/JPO-D-13-0130.1.

Brearley, J. A., K. L. Sheen, A. C. Naveira Garabato, D. A. Smeed, K. G. Speer, A. M. Thurnherr, M. P. Meredith, and S. Waterman, 2014: Deep boundary current disintegration in Drake Passage. Geophys. Res. Lett., 41, 121-127, doi:10.1002/ 2013 GL058617.

Chelton, D. B., M. G. Schlax, and R. M. Samelson, 2011: Global observations of nonlinear mesoscale eddies. Prog. Oceanogr., 91, 167-216, doi:10.1016/j.pocean.2011.01.002.

Chen, R., S. T. Gille, J. L. McClean, G. R. Flierl, and A. Griesel, 2015: A multi-wavenumber theory for eddy diffusivities and its application to the southeast Pacific (DIMES) region. J. Phys. Oceanogr., 45, 1877-1896, doi:10.1175/JPO-D-14-0229.1.

Chereskin, T. K., L. D. Talley, and B. M. Sloyan, 2010: Nonlinear vorticity balance of the Subantarctic Front in the southeast Pacific. J. Geophys. Res., 115, C06026, doi:10.1029/ 2009JC005611.

Davis, R. E., 1991: Observing the general circulation with floats. DeepSea Res., 38A, S531-S571, doi:10.1016/S0198-0149(12)80023-9.

Faure, V., and K. Speer, 2012: Deep circulation in the eastern South Pacific Ocean. J. Mar. Res., 70, 748-778, doi:10.1357/ 002224012806290714.

Ferrari, R., and M. Nikurashin, 2010: Suppression of eddy diffusivity across jets in the Southern Ocean. J. Phys. Oceanogr., 40, 1501-1519, doi:10.1175/2010JPO4278.1.

—, C. Provost, A. Renault, N. Sennéchael, N. Barré, Y.-H. Park, and J. H. Lee, 2012: Circulation in Drake Passage revisited using new current time series and satellite altimetry: 1 . The Yaghan Basin. J. Geophys. Res., 117, C12024, doi:10.1029/ 2012JC008264.

,-- , N. Sennéchael, and J.-H. Lee, 2013: Circulation in Drake Passage revisited using new current time series and satellite altimetry: 2. The Ona Basin. J. Geophys. Res. Oceans, 118, 147-165, doi:10.1002/2012JC008193.

Firing, Y. L., T. K. Chereskin, and M. R. Mazloff, 2011: Vertical structure and transport of the Antarctic Circumpolar Current in Drake Passage from direct velocity observations. J. Geophys. Res., 116, C08015, doi:10.1029/2011JC006999.

Fu, L.-L., 2009: Pattern and velocity of propagation of the global ocean eddy variability. J. Geophys. Res., 114, C11017, doi:10.1029/2009JC005349.

Garraffo, Z. D., A. J. Mariano, A. Griffa, C. Veneziani, and E. P. Chassignet, 2001: Lagrangian data in a high-resolution numerical simulation of the North Atlantic: I. Comparison with in situ drifter data. J. Mar. Syst., 29, 157-176, doi:10.1016/ S0924-7963(01)00015-X.

Gille, S. T., 2003a: Float observations of the Southern Ocean. Part I: Estimating mean fields, bottom velocities, and topographic steering. J. Phys. Oceanogr., 33, 1167-1181, doi:10.1175/ 1520-0485(2003)033<1167:FOOTSO > 2.0.CO; 2 .

- 2003b: Float observations of the Southern Ocean. Part II: Eddy fluxes. J. Phys. Oceanogr., 33, 1182-1196, doi:10.1175/ 1520-0485(2003)033<1182:FOOTSO > 2.0.CO; 2.

Griesel, A., C. Eden, N. Koopmann, and E. Yulaeva, 2015: Comparing isopycnal eddy diffusivities in the southern ocean with predictions from linear theory. Ocean Modell., 94, 33-45, doi:10.1016/j.ocemod.2015.08.001.

Hancock, C., and K. Speer, 2013a: Critical layers and isopycnal mixing in the Southern Ocean RAFOS float data report February 2010-February 2012. FSU Marine Field Group Rep. 13-1,153 pp. [Available online at http://gfdi.fsu.edu/Research/ PDFs/CLIMS.]

$\longrightarrow$, and — 2013b: Diapycnal and Isopyncal Mixing Experiment in the Southern Ocean RAFOS float data report February 2009-February 2012. FSU Marine Field Group Rep. 132, 217 pp. [Available online at http://gfdi.fsu.edu/Research/ PDFs/DIMES.]

Hua, B. L., J. C. McWilliams, and P. Klein, 1998: Lagrangian accelerations in geostrophic turbulence. J. Fluid Mech., 366, 87-108, doi:10.1017/S0022112098001001.

Hughes, C. W., 2005: Nonlinear vorticity balance of the Antarctic Circumpolar Current. J. Geophys. Res., 110, C11008, doi:10.1029/2004JC002753.

_ , and P. D. Killworth, 1995: Effects of bottom topography in the large-scale circulation of the Southern Ocean. J. Phys. Oceanogr., 25, 2485-2497, doi:10.1175/1520-0485(1995)025<2485: EOBTIT $>2.0 . \mathrm{CO} ; 2$.

Karsten, R. H., and J. Marshall, 2002: Testing theories of the vertical stratification of the ACC against observations. Dyn. Atmos. Oceans, 36, 233-246, doi:10.1016/S0377-0265(02)00031-3.

Killworth, P., 1992: An equivalent-barotropic mode in the fine resolution model. J. Phys. Oceanogr., 22, 1379-1387, doi:10.1175/1520-0485(1992)022<1379:AEBMIT>2.0.CO;2.

Klocker, A., R. Ferrari, and J. H. LaCasce, 2012: Estimating suppression of eddy mixing by mean flows. J. Phys. Oceanogr., $\mathbf{4 2}$, 1566-1576, doi:10.1175/JPO-D-11-0205.1.

LaCasce, J., 2008: Statistics from Lagrangian observations. Prog. Oceanogr., 77, 1-29, doi:10.1016/j.pocean.2008.02.002.

_ , and P. Isachsen, 2010: The linear models of the ACC. Prog. Oceanogr., 84, 139-157, doi:10.1016/j.pocean.2009.11.002. 
_ , R. Ferrari, J. Marshall, R. Tulloch, D. Balwada, and K. Speer, 2014: Float-derived isopycnal diffusivities in the DIMES experiment. J. Phys. Oceanogr., 44, 764-780, doi:10.1175/ JPO-D-13-0175.1.

Lenn, Y., T. Chereskin, J. Sprintall, and E. Firing, 2007: Mean jets, mesoscale variability and eddy momentum fluxes in the surface layer of the Antarctic Circumpolar Current in Drake Passage. J. Mar. Res., 65, 27-58, doi:10.1357/002224007780388694.

Lumpkin, R., and K. Speer, 2007: Global ocean meridional overturning. J. Phys. Oceanogr., 37, 2550-2562, doi:10.1175/ JPO3130.1.

_ - A.-M. Treguier, and K. Speer, 2002: Lagrangian eddy scales in the northern Atlantic Ocean. J. Phys. Oceanogr., 32, 2425 2440, doi:10.1175/1520-0485-32.9.2425.

Marshall, J., and K. Speer, 2012: Closure of the meridional overturning circulation through Southern Ocean upwelling. Nat. Geosci., 5, 171-180, doi:10.1038/ngeo1391.

Mazloff, M., P. Heimbach, and C. Wunsch, 2010: An eddypermitting Southern Ocean state estimate. J. Phys. Oceanogr., 40, 880-899, doi:10.1175/2009JPO4236.1.

Meredith, M. P., and Coauthors, 2011: Sustained monitoring of the Southern Ocean at Drake Passage: Past achievements and future priorities. Rev. Geophys., 49, RG4005, doi:10.1029/ 2010RG000348.

Middleton, J. F., 1985: Drifter spectra and diffusivities. J. Mar. Res., 43, 37-55, doi:10.1357/002224085788437334.

Nakamura, N., 2008: Sensitivity of global mixing and fluxes to isolated transport barriers. J. Atmos. Sci., 65, 3800-3818, doi:10.1175/2008JAS2641.1.

Naveira Garabato, A. C., R. Ferrari, and K. L. Polzin, 2011: Eddy stirring in the Southern Ocean. J. Geophys. Res., 116, C09019, doi:10.1029/2010JC006818.

— A. P. Williams, and S. Bacon, 2014: The three-dimensional overturning circulation of the Southern Ocean during the WOCE era. Prog. Oceanogr., 120, 41-78, doi:10.1016/ j.pocean.2013.07.018.

Ollitrault, M., and A. Colin de Verdière, 2002: SOFAR floats reveal midlatitude intermediate North Atlantic general circulation. Part II: An Eulerian statistical view. J. Phys. Oceanogr., 32, 2034-2053, doi:10.1175/1520-0485(2002)032<2034: SFRMIN $>2.0 . \mathrm{CO} ; 2$.

Orsi, A. H., T. Whitworth, and W. D. Nowlin, 1995: On the meridional extent and fronts of the Antarctic Circumpolar Current. DeepSea Res. I, 42, 641-673, doi:10.1016/0967-0637(95)00021-W.

Phillips, H. E., and S. R. Rintoul, 2000: Eddy variability and energetics from direct current measurements in the Antarctic Circumpolar Current south of Australia. J. Phys. Oceanogr., 30, 3050-3076, doi:10.1175/1520-0485(2000)030<3050: EVAEFD $>2.0 . \mathrm{CO} ; 2$.

— , and N. L. Bindoff, 2014: On the nonequivalent barotropic structure of the Antarctic Circumpolar Current: An observational perspective. J. Geophys. Res. Oceans, 119, 5221-5243, doi:10.1002/2013JC009516.
Rupolo, V., V. Artale, B. L. Hua, and A. Provenzale, 1996: Lagrangian velocity spectra at $700 \mathrm{~m}$ in the western North Atlantic. J. Phys. Oceanogr., 26, 1591-1607, doi:10.1175/ 1520-0485(1996)026<1591:LVSAMI >2.0.CO;2.

Sallée, J. B., K. Speer, and R. Morrow, 2008a: Southern ocean fronts and their variability to climate modes. J. Climate, 21, 3020-3039, doi:10.1175/2007JCLI1702.1.

$-, \ldots,-$, and R. Lumpkin, 2008b: An estimate of Lagrangian eddy statistics and diffusion in the mixed layer of the Southern Ocean. J. Mar. Res., 66, 441-463, doi:10.1357/ 002224008787157458 .

Sciremammano, F., Jr., R. D. Pillsbury, W. D. Nowlin Jr., and T. Whitworth III, 1980: Spatial scales of temperature and flow in Drake Passage. J. Geophys. Res., 85, 4015-4028, doi:10.1029/JC085iC07p04015.

Sloyan, B. M., and S. R. Rintoul, 2001: The Southern Ocean limb of the global deep overturning circulation. J. Phys. Oceanogr., 31, 143-173, doi:10.1175/1520-0485(2001)031<0143: TSOLOT $>2.0 . \mathrm{CO} ; 2$.

Smith, K. S., and G. K. Vallis, 2001: The scales and equilibration of midocean eddies: Freely evolving flow. J. Phys. Oceanogr., 31, 554-571, doi:10.1175/1520-0485(2001)031<0554: TSAEOM $>2.0 . \mathrm{CO} ; 2$.

Sokolov, S., and S. R. Rintoul, 2009: Circumpolar structure and distribution of the Antarctic Circumpolar Current fronts: 1. Mean circumpolar paths. J. Geophys. Res., 114, C11018, doi:10.1029/2008JC005108.

Swenson, M. S., and P. P. Niiler, 1996: Statistical analysis of the surface circulation of the California Current. J. Geophys. Res., 101, 22 631-22 645, doi:10.1029/96JC02008.

Talley, L., 2013: Closure of the global overturning circulation through the Indian, Pacific, and Southern oceans: Schematics and transports. Oceanography, 26, 80-97, doi:10.5670/oceanog.2013.07.

Taylor, G., 1921: Diffusion by continuous movements. Proc. London Math. Soc., 20, 196-212.

Thompson, A. F., 2008: The atmospheric ocean: Eddies and jets in the Antarctic Circumpolar Current. Philos. Trans. Roy. Soc. London, A366, 4529-4541, doi:10.1098/rsta.2008.0196.

- 2010: Jet formation and evolution in baroclinic turbulence with simple topography. J. Phys. Oceanogr., 40, 257-278, doi:10.1175/2009JPO4218.1.

—, and A. C. Naveira Garabato, 2014: Equilibration of the Antarctic Circumpolar Current by standing meanders. J. Phys. Oceanogr., 44, 1811-1828, doi:10.1175/JPO-D-13-0163.1.

— P. H. Haynes, C. Wilson, and K. J. Richards, 2010: Rapid Southern Ocean front transitions in an eddy-resolving ocean GCM. Geophys. Res. Lett., 37, L23602, doi:10.1029/2010GL045386.

Tulloch, R., and Coauthors, 2014: Direct estimate of lateral eddy diffusivity upstream of Drake Passage. J. Phys. Oceanogr., 44, 2593-2616, doi:10.1175/JPO-D-13-0120.1.

Warren, B. A., 1990: Suppression of deep oxygen concentrations by Drake Passage. Deep-Sea Res., 37A, 1899-1907, doi:10.1016/ 0198-0149(90)90085-A. 